\title{
Die Reformfakultät und die 68er
}

- Der Zeitzeuge und der Zeithistoriker nach vierzig Jahren -

Der Zeitzeuge berichtet über das Geschehen, das er wahrnahm oder an dem er beteiligt war. $\mathrm{Zu}$ seinem Bericht gehören nicht nur Tatsachen, sondern auch das Atmosphärische und seine eigene damalige Wertung. Aber das Geschehen liegt vierzig Jahre zurück, und sein damaliger Bericht und sein damaliges Urteil bedürfen daher der Ergänzung und der Überprüfung. Der Zeitzeuge wird damit zum Zeithistoriker ${ }^{1}$ und bezieht als solcher seine eigene Entwicklung in seine Würdigung und das individuelle Geschehen in die größeren Zusammenhänge ein. Diese Darstellung habe ich nunmehr in einem zweiten Teil verselbstständigt und damit die Struktur meines Vortrags verändert. Die Vortragsform habe ich beibehalten.

\section{A. Der Zeitzeuge}

I. Mein Bericht bezieht sich auf die Provinz, auf Gießen. Ich gebe also nur ein punktuelles Bild, zumal die Brennpunkte der 68er Bewegung Berlin und Frankfurt ${ }^{2}$ waren, und suche die Perspektive zum Vergleich zu öffnen. Mein Bericht setzt fünf Jahre früher ein, mit der Neugründung einer Reformfakultät ohne personelle Altlasten aus der braunen Vergangenheit. Ihren Angehörigen fehlte jedenfalls „unter den Talaren der Muff von tausend Jahren“. ${ }^{3}$ Das Verdikt des Göttinger Verwaltungsrechtlers Werner

1 Zum Verhältnis beider zueinander vgl. ausführlich Thilo Ramm, Die Justiz und das „dritte Reich“, das „dritte Reich“ und die Justiz. Positionen und Perspektiven - Probleme und Lösungen, in: Gerhart Pauli/Thomas Vormbaum (Hg.), Justiz und Nationalsozialismus - Kontinuität und Diskontinuität (= Juristische Zeitgeschichte Abt. 2, Forum juristische Zeitgeschichte 14), Berlin 2003, 31 ff. Bereits früher: Ders., Zeitzeuge und Zeithistoriker. Fragen und Anmerkungen zu Sebastian Haffner, Neue Politische Literatur 44 (1999), 496-502. Die Umkehrung, wie sie Fritz Stern am Beispiel Jakob Burckhardts in: Das feine Schweigen, München 1999,7 . demonstriert, ist ebenso möglich. Der Historiker wird dann zum besonders kritischen Zeitzeugen.

2 Oder gehört auch Marburg dazu? Die vom Hochschulverband herausgegebene Denkschrift zum 450jährigen Bestehen der Philipps-Universität zu Marburg „Bilanz einer Reform“ 1977 enthält jedenfalls eine Fülle von Informationen über das dortige Einzelgeschehen. Ut audiatur et altera pars: Barbara Dietrich/Joachim Perels (Hg.), Wolfgang Abendroth. Ein Leben in der Arbeiterbewegung. Gespräche, 2. Aufl. Frankfurt 1977, 258 ff.

3 Dieses Wort wurde zur Kampfaussage der 68er. Es kommentierte den Einzug des Lehrkörpers der Hamburger Universität. Diese war allerdings gerade ein halbes Jahrhundert alt. Ihre Gründung gehörte wie die der Frankfurter und Kölner zu den Erneuerungsversuchen am Ende des Kaiserreichs. 
Weber „links von Mao“" hat wohl Spiros Simitis mit seiner Dissertation über die „Faktischen Vertragsverhältnisse als Ausdruck der gewandelten sozialen Funktion“ $(1957)^{5}$ und mir gegolten, der über Ferdinand Lassalle promoviert (1950), mit einer Arbeit über die Rechtstheorie der Frühsozialisten in Freiburg habilitiert worden war (1953), sich dann als Gutachter der IG Metall mit dem damaligen Papst des Arbeitsrechts Hans Carl Nipperdey angelegt hatte und mit seinem Wiesbadener Festvortrag zum 17. Juni 1953 einen Sturm, im hessischen Wasserglas verursacht hatte. Es war kaum auf die beiden Öffentlichrechtler gemünzt, Werner Mallmann, den Frankfurter Ordinarius und Redakteur der „Juristenzeitung“, und den Bonner Ordinarius Helmut Ridder, der nach seinem Essay über die Meinungsfreiheit als große Hoffnung der Staatsrechtslehre galt und das Staatslexikon der katholischen Görres-Gesellschaft neu herausgab.

Die Hoffnung, weitere renommierte Außenseiter in Gießen zu versammeln, erwies sich als trügerisch, als sich der Tübinger Strafrechtler Baumann versagte. Schon vorher konnten die Politikwissenschaftler Wolfgang Abendroth in Marburg und Karl Dietrich Bracher in Bonn nicht gewonnen werden. Die traditionellen angesehenen Wirkungsstätten waren eben reizvoller als die Konzentrierung der Außenseiter an der ,universitas avis montana" (so Ridder). Selbst das Absehen von der Berufungshürde der Habilitation gelang nur in einem Einzelfall. Die Rekrutierung des Lehrkörpers blieb daher auf die Nichtordinarien beschränkt, die auszuwählen damals schwierig genug war.

Ohne dass dies wie 1965 und 1966 in Tübingen, München und Berlin die Studenten gewünscht hatten, veranstalteten die Juristen 1968 eine Ringvorlesung „Rechtswissenschaft und Nationalsozialismus“. Die Fragestellung war eigentlich höchst einfach. Es galt die Bestandsaufnahme durchzuführen: Was war in den zwölf Jahren des „Dritten Reichs" in den einzelnen Disziplinen geschehen, und was waren die Konsequenzen für die Gegenwart? Lücken blieben dabei freilich, etwa für das Wirtschaftsrecht und das Familienrecht, und im Übrigen konnte jeder Teilnehmer seine Veranstaltung aus-

4 Oder muss auf den Äußernden und die Fakultät abgestellt werden? Zu Werner Weber vgl. Michael Stolleis, Geschichte des öffentlichen Rechts in Deutschland, Bd. 3, München 1999, 287, zu Göttingen Eva Schumann, Die Göttinger Rechts- und Staatswissenschaftliche Fakultät 1933-1955, in: Dies. (Hg.), Kontinuitäten und Zäsuren. Rechtswissenschaft und Justiz im „Dritten Reich“ und in der Nachkriegszeit, Göttingen 2008, 65.

5 Seine Frankfurter Habilitationsschrift von 1963 ,Der Sozialstaatsgrundsatz in seiner Bedeutung für Familie und Unternehmen“" war und ist unveröffentlicht. Teilveröffentlichung in „Zum Strukturwandel des Familienrechts“, in: Spiros Simitis/Gisela Zenz, Familie und Familienrecht Bd. 1, Frankfurt 1975, 132. 
gestalten wie er wollte. ${ }^{6}$ Mit der Vorlesung „Arbeitsrecht und Nationalsozialismus“ suchte ich allerdings ein Beispiel zu geben. Nicht alle machten freilich mit. Von zwei erhofften Mitstreitern versagte der eine (Simitis) die Teilnahme, weil er nicht wisse, was Recht, der andere (Kübler), weil er nicht wisse, was Nationalsozialismus sei. Der am besten unterrichtete Zeitzeuge Mallmann war sich über die Folgen eines wahrheitsgemäßen Berichts in der damaligen Universitätslandschaft klar. Ich hätte übrigens auch selbst gewarnt sein müssen. Als der Göttinger Arbeitsrechtler Wolfgang Siebert bei einem Besuch in Freiburg mich als Privatdozenten begrüßte, bemerkte er ingrimmig, ich hätte ja seine früheren Äußerungen festgehalten. Aber dies war doch in einer wissenschaftlichen Auseinandersetzung selbstverständlich - oder?

Die Gießener Neugründung war frei von Altlasten aus dem „Dritten Reich“. Sie brauchte sich daher nicht mit den Angriffen auf die „braune Universität“ zu befassen, wie sie in Nachfolge von Rolf Seeliger stattfanden. ${ }^{7}$ Die Chance für den Neuanfang war gegeben, auch mit (oder gerade wegen) der Ablehnung personeller Hilfeleistungen beim Aufbau durch andere Fakultäten. Das Stichwort war die Studienreform, und hier blieb Gießen mit seinem Entwurf einer Studienordnung durchaus im Rahmen des Üblichen. Ich hatte ursprünglich vorgeschlagen, ein „Generalsemester“ mit den Vorlesungen „Die politische, wirtschaftliche und soziale Entwicklung Deutschlands im 19. und 20. Jahrhundert“, „Gesellschaft und Staat nach dem Grundgesetz“ und „Die Freiheitsrechte, Geschichte und geltendes Recht" ${ }^{\text {" } 8}$ voranzuschicken und dadurch für eine politisch-historische Basis zu sorgen. Die Einführungsveranstaltungen waren nunmehr Sache der Fachdisziplinen. Als Zivilrechtler konnte ich auf meinen Freiburger Probevortrag „Grundrechte und bürgerliches Recht“, auf meine Vorlesungen über den Allgemeinen Teil des BGB in stets wechselnden Perspektiven und auf meine Auseinandersetzung mit dem BAG zurückgreifen, ${ }^{9}$ die dann 1965 die Basis meiner Darstel-

6 Die weiteren Veranstaltungen waren: Herbert Jäger, Strafrecht und nationalsozialistische Gewaltverbrechen, Dieter Schwab, Zum Selbstverständnis der historischen Rechtswissenschaft im Dritten Reich, Wolfgang Grunsky, Gesetzesauslegung durch die Zivilgerichte im Dritten Reich und Helmut Ridders Zur Verfassungsdoktrin des NS-Staates. Sie wurden sämtlich von der Kritischen Justiz veröffentlicht und als Hilfe bei ihrem Start gemeint. Vgl. zur Publikationsgeschichte auch den Briefwechsel zwischen Grunsky und der Redaktion 1969, 160. In ihrer Sammelpublikation „Der Unrechtsstaat. Recht und Justiz im Nationalsozialismus“ von 1979 hat die KJ Grunsky und Schwab weggelassen und Roderich Wahsners Kritik an Schwab (KJ 6 [1973], 172) veröffentlicht. Wahsner war der Assistent von Schwab und vorher bei mir, übrigens in Kenntnis seiner marxistischen Überzeugungen, wissenschaftlicher Hilfsarbeiter gewesen, der die Übersetzung von Folke Schmidts Arbeiten lektoriert und die Anmerkungen zur Neuedition von Sinzheimer-Fraenkels Chronik der Justiz eingeleitet von Kirchheimer 1968 verfasst hatte.

7 Vgl. seine sechs Broschüren im Selbstverlag von 1965 bis 1968. Seeliger druckte Äußerungen während des „Dritten Reichs“ ab und erbat dazu Stellungnahmen. Solche erfolgten gerade bei den Juristen nur in geringem Maße. Seeliger hat 1968 auch die Broschüre „Die außerparlamentarische Opposition" veröffentlicht.

8 Vgl. Gerhard Köbler, Giessener Juristische Vorlesungen (= Arbeiten zur Rechts- und Sprachwissenschaft 21), Gießen 1982, XLI.

9 Deren Beginn bildete die Probevorlesung. Mein Rechtsgutachten für die IG Metall setzte bei dieser Fragestellung ein und behandelte die grundrechtlich geschützte Freiheit der Streikwillensbildung. Ich hatte mich immer gefragt, wieso Nipperdey und ich die theoretische Ausgangsposition gemeinsam hatten, aber dann zu so unterschiedlichen Ergebnissen kamen. 
lung des Grundgesetzes bildeten. ${ }^{10}$ Meine theoretische Basis war der Verfassungspositivismus mit strenger Bindung des Gesetzgebers an die Verfassung und der Bindung der Rechtsprechung wiederum an ihn. Ich hielt also an der klassischen Position der Gewaltenteilung fest, auch später (1973) in einem Streitgespräch mit Josef Esser (Richtermacht, Methodenstreit und Grundgesetzauslegung), in dem ich mich auch gegen seine Lehre vom Vorverständnis wandte.

Was war also Gießen? In seiner Eröffnungsansprache bezeichnete sie Mallmann als Studienfakultät, die „heute eine Studienreformfakultät sein“ müsse. Sie repräsentierte sich in ihrer öffentlichen Vorstellung als solche, wobei ich die Urteilsanmerkung übernahm. Wesentlich war die Unterstützung der Vorlesung durch kleine Arbeitsgemeinschaften. ${ }^{11}$ Ich preschte damals vor mit meiner dreibändigen „Einführung in das Privatrecht. BGB Allgemeiner Teil“" (1969/70), ${ }^{12}$ die parallel zu Karl Kroeschells dreibändiger „Deutschen Rechtsgeschichte“ geschrieben und gemeinsam veröffentlich werden sollte. ${ }^{13}$ In ein Lehr- und Lernbuch aufgeteilt, mit Materialien und Problemdiskussionen versehen und auch auf das Recht der DDR eingehend, bot es mehr als die schon damals gelegentlich verwandten Skripten. ${ }^{14}$ Es war ein Buch, das ich gern selbst als Studienanfänger gehabt hätte. Es war eine Revolution, weil es die Vorlesung ersetzen sollte. ${ }^{15}$ An deren Stelle sollte vielmehr die Lektüre durch die Studenten und die Durchsprache in Arbeitsgemeinschaften, der Dialog mit den Lesern, treten.

Die 68er verstanden meine didaktischen Bemühungen, dem Studienanfänger die Einführung in die fremde Welt des Rechts zu erleichtern, ${ }^{16}$ natürlich anders. Die bei den Abiturienten verständliche allgemeine Antipathie gegen - wiederum - eine „Verschu-

10 Sie war der Hauptteil meiner Schrift Der Arbeitskampf und die Gesellschaftsordnung des Grundgesetzes. Beitrag zu einer Verfassungslehre (= Arbeits- und sozialrechtliche Studien 12), Stuttgart 1965, auch in: Zum freiheitlichen sozialen Rechtsstaat. Ausgewählte Schriften (= Studien zur europäischen Rechtsgeschichte 112), Frankfurt 1999, 21 (mit dem Titel Gesellschaftsordnung und GG - ohne die Abschnitte über den Arbeitskampf).

11 Zur allgemeinen Entwicklung vgl. Heinhard Steiger, Das Giessener Modell, in: Walter Gropp u.a. (Hg.), Rechtswissenschaft im Wandel. Festschrift des Fachbereichs Rechtswissenschaft zum 400jährigen Gründungsjubiläum der Justus-Liebig-Universität Gießen, Tübingen 2007, $65 \mathrm{ff}$.

12 2. Aufl. 1974/75.

13 Dies ist nicht geschehen. Vorgesehen war zunächst der Beck Verlag, mit dem ich vor meiner Reise in die USA abschloss. Kroeschell wechselte aber zum Rowohlt-Verlag. Sein 3. Band erschien erstmals 1989. Alle drei Bände sind in neusten Auflagen 2008 publiziert worden.

14 Ich hatte ein solches für das Eherecht verfasst, aus dem dann später meine Veröffentlichung von 1985 hervorgegangen ist.

15 Vgl. dazu meinen Bericht in JuS 10 (1970), 308.

16 Dazu zählten auch die Anleitungen zur Rechtstechnik. Ich dehnte sie mit der Kritik und Analyse richterlicher Entscheidungen auf meine Arbeitsgemeinschaft über die höchstrichterliche Rechtsprechung aus. 
lung“ bekam als Widerstand gegen den ,technokratischen Disziplinierungsversuch“17 einen neuen Namen. Aber gehört nicht zur Freiheit der Erwerb der Fähigkeit, sie zu nutzen? Für die Studenten wurden jedenfalls die von mir 1966 veröffentlichten Quellentexte aus der Weimarer Zeit „Arbeitsrecht und Politik“ ungleich wichtiger, und zwar die marxistischen Abhandlungen der drei Sinzheimer-Schüler Ernst Fraenkel, Franz L. Neumann und Otto Kahn-Freund. ${ }^{18}$ Sie wirkten 1968 wie eine Brandfackel.

II. In Gießen begann die Auseinandersetzung mit den 68ern bei der Notstandsverfassung. Das politische Aufbegehren war keineswegs unverständlich. Die Bundesregierung erstrebte die Souveränität, und die amerikanische Besetzungsmacht machte davon die Verteidigung der Ordnung im Falle eines Umsturzes abhängig. Die in der DDR konzentrierte kommunistische Gefahr schwebte ja als Damoklesschwert über der Bonner Republik. Andererseits aber war das Misstrauen gegen die autoritäre Regierung der Bonner Republik und ihre Freunde weit verbreitet - der Aufruhr begann bekanntlich mit den „Jubelpersern“ beim Empfang des Schahs in Berlin. Den 68ern gelang jedenfalls die perfektionistische Absicherung des Notstandsfalls, von der noch jetzt die Verunstaltung des Grundgesetzes zeugt. Es war ein Danaersieg. ${ }^{19}$ Ich habe mich damals gefragt und tue dies heute noch, ob die verfassungsrechtlich perfektionistisch getroffene Regelung auch wirklich praktikabel sei. Ich erinnere mich daran, damals Roderich Wahsner aufgefordert zu haben, das Ergebnis in seiner Dissertation zu behandeln. Er hat aber lieber ein anderes Thema gewählt, ein anderes neues „heißes Eisen".

Die Gewaltbereitschaft war schon damals spürbar. Ich erinnere mich noch genau an die Stadien: Am Anfang stand das Gedicht über den Kaufhausbrand. Es folgte dann die Brandstiftung. Die Gewalt gegen Sachen wurde durch die Gewalt gegen Personen und die von der „Roten Armee Fraktion“ organisierten politischen Morde abgelöst. Ihre zynische Begleitung, die Bekundung der „klamm-heimlichen Freude“ über die Ermordung Schleyers, war abstoßend. Der Terror der 68er unterschied sich jedenfalls

17 So die unter vielfachen Aspekten interessante, mir leider erst jetzt zur Kenntnis gekommene Rezension des Studenten Friedhelm Hase in DuR. Mein damaliger, fast zwanzig Jahre jüngerer, wissenschaftlicher Mitarbeiter Ulrich Mückenberger, Koautor für die Behandlung des Persönlichkeitsrechts in der ersten Auflage, verkannte in einer ausführlichen handschriftlichen Kritik die selbstverständliche Bindung an das geltende Recht und plädierte für die damals beliebte exemplarische Rechtsfortbildung.

18 Ich hatte während eines England-Aufenthalts Otto Kahn-Freund, den Verfasser des ,sozialen Ideals des Reichsarbeitsgerichts", kennen gelernt und verdankte ihm die Kenntnis der Weimarer Situation. Ich stellte den Schriften Potthoffs „Einwirkung der Reichsverfassung auf das Arbeitsrecht“" (1925) voran. Die Publikation war von mir als Schützenhilfe gegen das BAG gedacht. Damit wollte ich demonstrieren, dass in der Weimarer Republik eine scharfe Auseinandersetzung möglich gewesen war. Ich hatte die Manuskripte beim Luchterhand Verlag schon Jahre vorher eingereicht. Die Publikation erfolgte dann plötzlich, als es dem Lektor Frank Benseler gelang, den Verleger zu überreden. Dem viel zu weit greifenden Titel ist meine knappe Einleitung nicht gerecht geworden.

19 Ich habe an ihm als Arbeitsrechtler mitgewirkt (AuR 15 [1967], 33) und erinnere mich noch an die Veranstaltung in Marburg, in der der Soziologe Hofmann den damaligen Bundesinnenminister Ernst Benda in äußerst unangenehmer Weise angriff. Meine später im roroTaschenbuch veröffentlichte Stellungnahme war eine frühere, nicht dem letzten Stand entsprechende Fassung. Ich hielt die ganze Diskussion für verfehlt, da der Notstandsfall keine perfektionistische Regelung verträgt. 
nicht vom nationalsozialistischen des Jahres 1933, wie Mallmann anlässlich des Besuchs einer Veranstaltung des Hessischen Rundfunks in Frankfurt bemerkt. Damals bezeichnete einer der Redner die Bonner Republik als Bananenrepublik - bei aller Antipathie, dies war sie nun wirklich nicht.

Nach Gewalt brauchte man nicht weit zu suchen. Das Gießener soziologische Seminar der Adorno-Schülerin Helge Proß wurde „sozialisiert“ - sie hatte in ihm nichts mehr zu sagen. Abendroth ist es offenbar in Marburg ebenso gegangen. Der Kampf der 68er richtete sich eben gegen jede Hierarchie, auch gegen die der eigenen Führer. Die 68er stellten das Gewaltmonopol des Staates infrage und nahmen für sich (oder auch für eine neue Ordnung?) die Gewalt mit Selbstverständlichkeit in Anspruch und schufen damit eine allgemeine Unsicherheit. Als Senatsmitglied haben sie mich einmal einige Stunden eingesperrt - mit welchem Recht eigentlich?

Gewalt erzeugt die Solidarität der Angegriffenen. Dies führte in der neuen GruppenUniversität zu merkwürdigen Ergebnissen. Bei der Gießener Präsidentenwahl mahnte ich die Professoren zur Einigkeit gegen den Assistenten-Kandidaten Neumann, dem ich ein ,gestörtes Verhältnis zum Recht“ vorwarf, und wurde deswegen in der „Frankfurter Rundschau“ als Reaktionär beschimpft. ${ }^{20}$ Aber ich hielt die Position des Ordinarius für verteidigungswürdig. Meine Kollegen scheuten übrigens die offene Konfrontation und zogen, so in den ,alten“ Fakultäten der Landwirtschaft und der Veterinärmedizin, im Vertrauen auf die überkommene Hierarchie die Einzelbearbeitung der wahlberechtigten Assistenten vor - womit sie übrigens erfolgreich waren. Durchlavieren ist eben stets eine in Zeiten der Gewalt praktizierte Kunst. Das Dankeschön für mich war die Wahl zu ihrem Vertreter im Hochschulverband.

III. Die historisch-politische Großwetterkarte verortet die 68er zwischen der Enttäuschung über die Vereinigten Staaten durch deren Vietnam-Politik und der Hoffnung auf einen Sozialismus mit menschlichen Zügen durch den Prager Frühling. Ihre spezifisch deutsche ideologische Komponente waren der Antifaschismus und ein emotionaler Marxismus. Beide waren keine tragfähigen Kräfte. Antifaschismus war die Formel vom Zusammenschluss der politischen Kräfte einschließlich der Kommunisten gegen den Nationalsozialismus. 1933 war er nicht erfolgt. Danach war er mit dem Hitler-StalinPakt von 1939 unvereinbar und nach 1945 taugte er nicht dazu, das politische Auseinanderdriften der Besatzungszonen, nach 1949 der beiden deutschen Teilstaaten zu überwinden. Die Auseinandersetzung mit dem Nationalsozialismus konnte jedenfalls nicht unter dem Vorzeichen des Antikapitalismus und mit Hilfe von Zitaten aus jener Zeit geführt werden. Die marxistisch begründete Kapitalismuskritik war ein Bürgerschreck, ein Gefühlsmarxismus, mit dem ich wissenschaftlich nichts anfangen konnte. Ich wusste dies, weil ich mich mit Marx und Engels im vorgesehenen zweiten Band meiner „großen Sozialisten als Rechts- und Sozialphilosophen“ (1955) eingehend be-

20 Ich forderte die Professoren auf, die Anhänger von Neumann seien, eine eigene Liste zu bilden und bezeichnete die damalige Universität als eine „Universität der institutionalisierten Konflikte“, in der der Präsident sich als streng an das Gesetz gebunden fühlender Schiedsrichter zu verstehen habe. 
fasst hatte. ${ }^{21}$ Der „Juristensozialismus“, 22 insbesondere Anton Menger, der eine sozialistische Ordnungskonzeption entwickelt hatte, war schon längst weiter gewesen. Zudem war der Marxismus die Leitideologie der DDR, des zweiten deutschen Teilstaats, dem im Unterschied zur Bonner Republik die Bestätigung durch freie Wahlen fehlte. Die Teilung Deutschlands hatte dem Bonner Republikaner - nicht aber seit dem Bau der Mauer im Jahr 1961 dem Bewohner der DDR - die Wahl zwischen den verschiedenen Gesellschaftsordnungen offen gelassen. Für mich war diese Entscheidung insofern selbstverständlich gewesen, als ich die Freiheit von Forschung und Lehre als die selbstverständliche Basis der Wissenschaft ansah. ${ }^{23}$ Die Wahlmöglichkeit wurde den 68ern durchaus zu recht entgegengehalten. Aber sie hätten doch auch einen freiheitlichen Sozialismus fordern und darauf die Wiedervereinigung stützen können. Gegen den emotionalen Marxismus vermochte ich natürlich nicht anzukommen: Wenn ein spanischer Richter über Marx sprach, dann hatte ich mit meiner Vorlesung „Marx und das Recht" keine Chancen.

IV. Meine „Einführung in das Privatrecht“ sollte in Arbeitsgemeinschaften durchgesprochen werden, die die Assistenten leiten sollten. Doch diese begehrten selbst die Herrschaft über die Lehre und wollten die Einführung nur als Material benutzen, etwa, ausgerechnet, neben dem Larenz. Daraufhin tauschte ich sie gegen höhersemestrige Studenten aus und koordinierte deren Arbeit als Arbeitsgemeinschaftsleiter in einem Seminar. Dies war die für die Studienanfänger didaktisch bessere Lösung und bewährte sich. ${ }^{24}$

Die persönliche Beziehung zwischen Assistenten und Professor wurde zerstört. An ihre Stelle trat die Gruppensolidarität der Assistenten. Aber der Kampf gegen die Hierarchie des Ordinarius ging jedenfalls in Gießen in die Leere, da diese nicht aus vorliberaler Zeit stammte, sondern durch die größere Sachkunde bei der Lösung der gemeinsamen Aufgabe der Studienreform bestimmt war. Meine Assistenten stammten noch aus meiner Freiburger Zeit als Nichtordinarius und waren mir durch die Opposition gegen die Bonner Republik sehr verbunden gewesen. Diese menschliche Verbundenheit und die gemeinsame Arbeit im Dienst an der Wissenschaft galt nun nicht mehr. Sie wurde durch die Gruppensolidarität ersetzt. ${ }^{25}$ Und ich empfand dies damals als Verrat, auch als Verrat an der Sache, denn es ging um die Reform der Rechtsinhalte. Als ich den Arbeitsvertrag eines Assistenten, den ich nur für die Zeit der Beurlaubung eines Habilitanden eingestellt hatte und der seine Hauptaufgabe im Kampf ge-

21 Allerdings trennte ich, vorgewarnt durch meine Vorerfahrungen mit den Lassalleanern, zwischen ihnen und den Nachfahren.

22 Vgl. hierzu meinen Aufsatz in den Quaderni Fiorentini 3/4 (1974/75), 7, wiederveröffentlicht in Thomas Vormbaum (Hg.), Juristische Zeitgeschichte Abt. 2 Bd. 6, 1 mit meinem Nachwort Anton Menger und die DDR oder Theorie und Praxis des Sozialismus, 17-70.

23 Die Worte von Franz Mestiz, des letzten Assistenten Hugo Sinzheimers, der nach der Entfernung von seinem Lehrstuhl in Pressburg zu seiner Tochter nach Frankfurt gegangen war "Ihr wisst gar nicht, wie gut Ihr es habt", klingen mir noch heute in den Ohren.

24 Ich denke, dies war eine Anleihe von dem großen englischen Frühsozialisten Robert Owen, der den Schulunterricht den älteren Schülern übertragen wollte. An sich war die Idee verblüffend einfach: Diese kannten die Verständnisschwierigkeiten und lösten sie für sich durch die Lehre.

25 Meine Erinnerung wird bestätigt durch die nachträgliche Lektüre einer Marburger Broschüre über den Assistentenstreik vom Januar 1970. 
gen die Ordinarienuniversität sah, nicht verlängerte, wurde ich boykottiert. Ich stellte dann zwei Landgerichtsräte als Assistenten ein. Aber mir ist unvergesslich, wie sehr sich mein Habilitand Bernhard Weller für seinen Vertreter einsetzte, obschon er selbst für die Justiz optierte und wegging. Ich habe sein wissenschaftliches Scheitern verstanden, nicht jedoch, dass uns der ehemalige Hausgenosse, Tennispartner und Freund nicht einmal zum Abschied besuchte.

Zur Sach-Auseinandersetzung ist noch der Kampf um die Habilitation nachzutragen. Eigentlich war dieser merkwürdig. Denn man verzichtete ohnehin auf sie in der 68er Vorzeigefakultät Bremen. Ich war und bin nach wie vor davon überzeugt, dass eine großangelegte Forschungsarbeit das Fundament für die spätere Lehre bildet, und sehe mich durch die Entwicklung meines ehemaligen Assistenten Manfred Weiß bestätigt. Ihn hatte ich durch einen Forschungsaufenthalt in Berkeley besonders gefördert. Seine Dissertation enttäuschte mich, da er sich mit einer Inhaltsangabe begnügte und die eigene wertende Position fehlte. Er war der Wortführer der Assistenten, hat sich aber auch nach seinem Weggang nie habilitiert. Die Frankfurter Fakultät beförderte ihn zum Dozenten. Dann wurde er Ordinarius in Hamburg II und kam von dort aus wieder zurück nach Frankfurt. Der Ersatz der Habilitationsschrift durch die Addition von Aufsätzen, die „Sammelhabilitation“, war ein fauler Kompromiss, den wir leider auch in Gießen praktizierten.

Immerhin gab es in Gießen als Ausnahme die wissenschaftliche Diskussion. Die eine bezog sich auf das Verhalten der Rechtshistoriker im „Dritten Reich“. Hier kritisierte Roderich Wahsner die Ausführungen Dieter Schwabs. ${ }^{26}$ An der anderen über die Stellung der Frau war ich unmittelbar beteiligt. ${ }^{27}$ Denn ich hatte schon früh die Gleichberechtigung bei der Bestimmung des Ehenamens eingefordert ${ }^{28}$ - und in ein Wespennest eingestochen. Dann hatte ich bei der Kernfrage der Eheführung der „Hausfrauenehe“" das Modell der Berufstätigenehe entgegengestellt und ihre gesetzgeberische Regelung propagiert. ${ }^{29}$ Ich fasste meine vom geltenden Recht ausgehende kritische Position in Thesen zusammen. Der ad hoc gebildete Arbeitskreis „Kritische Rechtswissenschaft" der 68er deutete demgegenüber den Ruf nach Emanzipation der Frau als Vortäuschung einer solchen des Mannes und forderte dazu auf, ,die strukturellen reellen Bedingungen mangelnder Emanzipation zu analysieren und die Voraussetzungen für eine allgemeine Emanzipation zu schaffen“. Es ging ihm also nicht um eine konkrete Diskussion von Reformen, sondern um die Durchsetzung einer anderen Gesellschaftsordnung. Aber bis dahin hätte doch einiges für die Gleichstellung der Frau geschehen können, nota bene, auch innerhalb der 68er-Bewegung?

Die Übernahme des Auftrags, in der Juristenzeitung meinen arbeitsrechtlichen Kollegen Wolfgang Däubler, den Wortführer der 1971 neugegründeten Bremer juristischen Fakultät der $68 \mathrm{er}$, zu rezensieren, ${ }^{30}$ führte zu weiteren Konflikten, die aller-

26 Dieter Schwab, Zum Selbstverständnis der historischen Rechtswissenschaft im Dritten Reich, KJ 1 (1968), 174; Wahsner (wie Anm. 6).

27 Vgl. zum Folgenden die chronologische Bibliographie meiner Schriften zum Familienrecht in meinem Sammelband Familienrecht - Verfassung - Geschichte - Reform, Tübingen 1996, 347.

28 Zeitschrift für das gesamte Familienrecht 9 (1962), 281.

29 JZ 23 (1968), 41, 90 im Sammelband 1996 (wie Anm. 27), 3.

30 JZ 33 (1978), 178. 
dings nur literarisch ausgetragen wurden. Eigentlich hatte ich Däubler nur bescheinigt, was auch seine Gesinnungsgenossen gesagt hatten: ein „klassisches Lehrbuch, wenn auch links herum" geschrieben zu haben. Ich war enttäuscht, weil die Grundpositionen zu einer Diskussion fehlten, zu der ich gleichwohl nach wie vor bereit war. Seine Fakultätsmitglieder beschwerten sich stattdessen über die von mir geübte „Perhorreszierung“ und „Denunziation“. Auch jetzt, nach vierzig Jahren finde ich keine solche. Ich hatte nur mich klar und unmissverständlich ausgedrückt, übrigens sehr viel zahmer als seinerzeit gegen Nipperdey. Die im Angriff nicht gerade zimperliche Linke war allerdings gegenüber Kritik überaus empfindsam. Ich replizierte. ${ }^{31}$ Herausgekommen ist bei alledem nichts. Ich ging auch fortan meine eigenen Wege und veranstaltete zusammen mit meinem neuen Assistenten Georg Hegenbart, einem Diplomjuristen und -soziologen, im WS 72/73 eine Vertiefungsvorlesung „Die Bedeutung der Familiensoziologie für das Familienrecht", zu der auch eine studentische Gruppe Diskussionsthesen zur Kleinfamilie und Gruppe beisteuerte.

Die Ansammlung von Außenseitern bürgte keineswegs für deren Einheit. ${ }^{32}$ In Gießen kam es zu einem für die anderen Fakultätsangehörigen nicht nachvollziehbaren schweren Konflikt zwischen Mallmann und Ridder, der zwar innerhalb der Grenzen kollegialen Umgangs ausgetragen wurde, aber doch lähmte. Denn beiden Gelehrten war die Führungsrolle zugedacht. Von Ridder gingen einige personelle Signale aus, wie die Vorschläge, den ehemaligen hessischen Kultusminister und späteren Bundesverfassungsrichter Erwin Stein und den aus der DDR geflohenen thüringischen Innenminister Helmut Külz zu Honorarprofessoren zu ernennen. Ihnen kam die Fakultät nach, und ich war nachher mit ihnen befreundet, während sich Ridder nicht mehr um sie kümmerte. Ridders Haltung ist mir nie recht klar geworden, auch nicht in der Rückschau. Er stellte durchaus hohe Ansprüche an die wissenschaftliche Qualität der Studenten und ging seine eigenen Wege mit seinen Schülern, denen er wohl die Redaktion der „Neuen Politischen Literatur“ und „linker“ Zeitschriften wie „Demokratie und Recht" und der „Blätter für deutsche und internationale Politik“ anvertraute. Ich habe sie nie gelesen. ${ }^{33}$ Auch damals hat jeder vor sich hin gearbeitet. Offensichtlich war

31 JZ 33 (1978), 792.

32 Ich denke, dabei handelt es sich um ein allgemeines Gesetz. Auch die von den Nazis verfolgten Emigranten bildeten keine in der politischen Zielsetzung einheitliche Gruppe. Um die Gruppenbildung bemühten sich Erika und Klaus Mann in den USA und Sebastian Haffner in Großbritannien erfolglos.

33 Erst jetzt habe ich Friedhelm Hases Verriss meiner „Einführung in das Privatrecht“ in DuR entdeckt. 
Ridder an der in Gießen gebotenen Chance zur Zusammenarbeit nicht ${ }^{34}$ - oder nicht mehr? $?^{35}$ - interessiert. Wie erklärt sich die selbstgewollte Isolation? ${ }^{36}$

Wie hat die Fakultät den Sturm der 68er überdauert? Vielleicht wäre ja alles ganz einfach gewesen. Wolfgang Grunsky ging abends mit seinen Studenten Bier trinken, was anscheinend genügte. Die Fakultätssitzungen verliefen unerfreulich. Unerträglich war in ihrem Auftreten die Kriminologin Eva Brauneck, die erste Fehlberufung der neuen Fakultät, die überdies zu meinen Lasten ging. Der Strafrechtler Tiedemann, der Öffentlichrechtler Sasse, der Rechtshistoriker Schwab und ich trafen uns am Wochenende zuvor und bestärkten uns gegenseitig. Über was in den Fakultätssitzungen gesprochen und was entschieden wurde, weiß ich nicht mehr. In Erinnerung geblieben ist mir allerdings die Besetzung des zivilprozessualen Lehrstuhls. Gegen den Vorschlag der Ordinarien sprachen sich die Assistenten und Studenten aus. Die letzteren hatten sich die Vorlesung eines Nichtordinarius angehört und waren von dessen Ordinarienschelte sehr angetan. Wir akzeptierten, weil wir seine konservative Grundhaltung kannten, und bekamen mit ihm den Rechtsaußen, den wir eigentlich gar nicht gewollt hatten. So konnte auch das Ergebnis der Politisierung der Berufung aussehen.

Entscheidend für das Schicksal Gießens waren aber weder Ridders neuer noch mein alter „schlechter Ruf“, sondern der mit der Abwanderung der erstberufenen Nichtordinarien Spiros Simitis, der mit seinen personellen Kenntnissen und seinem diplomatischen Geschick eine zentrale Rolle gespielt hatte, und des Raiser-Schülers Fritz Kübler einsetzende Erosionsprozess. Die alten angesehenen Fakultäten erwiesen sich eben doch als attraktiver als die Neugründung mit ihrem Reformanliegen. Und sie dokumentierten mit den Berufungen ihre Aufgeschlossenheit und bestätigten zugleich, dass Gießen keine Fakultät der Radikalen war.

34 Mich traf dies besonders, da Ridder Mitgutachter in der Verfassungsbeschwerde gegen das Urteil des BAG in Sachen schleswig-holsteinischer Metallarbeiterstreik gewesen war. Mein Buch „Der Arbeitskampf und die Gesellschaftsordnung des Grundgesetzes“ (wie Anm. 10) hat er nur freundlich-höflich entgegengenommen - sicherlich auch deswegen, weil die Überschreitung der fachdisziplinären Grenze ungewöhnlich war.

35 Retrospektiv, aus der Distanz von mehr als vierzig Jahren erkläre ich mir seine Position aus der Wandlung, den die Gießener Fakultät seit der Gründung genommen hatte: Sie war politisch angetreten (dazu hatte mein Festvortrag in Wiesbaden zum 10jährigen Gedenken des 17. Juni 1953, der ein Nachspiel im hessischen Landtag hatte, sicherlich beigetragen, forderte ich doch damals Verhandlungen zwischen beiden deutschen Teilstaaten) und dies mit dem Anspruch auf Auseinandersetzung mit dem Nationalsozialismus bestätigt, allerdings ohne dabei historisch vor der eigenen Türe zu kehren. Mit der Gewinnung der beiden Ordinarien und der Proklamation der Studienreform als ihrer Aufgabe wurde sie im Kreis der alten Fakultäten wettbewerbsfähig und war auf deren Nachwuchs zur weiteren Rekrutierung des Lehrkörpers angewiesen - und setzte damit die alte Rolle Gießens fort, Sprungbrett zu sein. Ridder blieb bei der alten Position und wurde zunehmend in der Hoffnung auf Reformen enttäuscht. Dies erklärt seine Hinwendung zu den 68ern. Aber er wurde auch von ihnen ein Stück abhängig, ebenso wie übrigens auch Abendroth. Ich denke heute, dass dem Katholiken Ridder das ursprüngliche tiefe Freiheitsbedürfnis abging. Insoweit bestand für mich eine Brücke zur Bonner Republik.

36 Eine Sammlung von Ridders Abhandlungen ist bisher nicht erfolgt. Dies ist schade, denn er gehört zur Rechtsgeschichte der Nachkriegszeit. Offenbar steht sie indessen bevor und wird von dem Bundesverwaltungsrichter Deiseroth besorgt. 
V. Ich komme zum letzten Akt. Eigentlich sind es zwei Akte gewesen. Der eine war der gegenüber dem hessischen Kultusminister von Friedeburg erklärte Rücktritt des Gießener Rektorats, dem auch Mallmann angehörte, vom 6. Mai 1970. Sie weigerten sich, an der Umstrukturierung der Universität, die das hessische Hochschulgesetz vorgenommen hatte, mitzuwirken. ${ }^{37}$ Die Allianz zwischen Professoren und dem Staat, die die Basis der Reformen gebildet hatte, war damit zu Ende. Der zweite letzte Akt betraf mich, den von Frau Matthäus-Maier als „Scheißliberalen“ Disqualifizierten, persönlich. Ich hatte bei der Studienreformdiskussion in Loccum vorgeschlagen, Universitätsstudium und juristischen Vorbereitungsdienst miteinander $\mathrm{zu}$ verbinden - was die beiden anderen Wortführer Wassermann und Wiethölter akzeptierten und Wassermann sodann verkündete. Der Vorteil dieses Vorschlags war leicht einzusehen. Die Ausbildungszeit konnte durch den Fortfall von Wartezeiten bei den Examina erheblich abgekürzt und die Ausbildung unter der Perspektive der wechselseitigen Befruchtung von Theorie und Praxis gründlich neu durchdacht werden. ${ }^{38}$ Ich hoffte auf einen gemeinsamen Vorschlag der Verzahnung, scheiterte aber damit an Wiethölter, ${ }^{39}$ dessen Dreistufenplan die ,problematisierende Informationsvermittlung“ und ,problematisierende Neustrukturierung des Rechts mit Einbau von Philosophie, Soziologie, Historie und Ökonomie" umfasste. Dies war ein Verweis auf seine Rechtskritik, eine imposante wissenschaftliche Leistung, die in den Beiträgen zum Funk-Kolleg enthalten waren und nachher als Fischer Taschenbücher ${ }^{40}$ weiteste Verbreitung erfuhren. Wiethölter und mich trennten indessen Welten: der Unterschied zwischen Revolution und einer Reform, die vom geltenden Recht ausging, aber die Spezialisierung der juristischen Fächer aufbrach und die Sozialwissenschaften als Hilfswissenschaften heranzog. ${ }^{41}$ Wiethölter hatte die größere publizistische Wirksamkeit voraus und fand überdies Resonanz beim „Arbeitskreis sozialdemokratischer Juristen“, deren zweiter Vor-

37 Vgl. hierzu Eva-Marie Felschow u.a., Krieg - Krise - Konsolidierung. Die „zweite Gründung“ der Universität Gießen nach 1945, Gießen 2008, 168.

38 Mein Gießener medizinischer Kollege von Uexküll hatte den Anstoß gegeben, das Studium von der Praxis neu zu sehen - was er für die Neugründung der medizinischen Fakultät durch die 1945 erhalten gebliebene medizinische Akademie getan hatte, vgl. Thilo Ramm, Die Praxis als Motivation des rechtswissenschaftlichen Studiums, Zeitschrift für Pädagogik 8 (1969) Beiheft Hochschuldidaktik, 79. Ich hatte schon vorher die Verlagerung des Prozessrechts in die Vorbereitungszeit gefordert, JZ 23 (1968), 294, 297. Die Vorschläge Dernburgs, Fischers und Zitelmanns, Studium und Vorbereitungsdienst miteinander zu verzahnen (vgl. Gerhart Husserl, Die Ausbildung der deutschen Juristen. Darstellung, Kritik und Reform [ = Veröffentlichungen des Arbeitskreises für Fragen der Juristenausbildung e.V. 2], Tübingen 1960, 171) hatte ich nicht gekannt.

39 Meine damalige Assistentin Gisela Zenz hatte ihn angefertigt. Wiethölter lehnte jedwede Diskussion hierüber ab. Im Loccumer Arbeitskreis zur Reform der Juristenausbildung (Hg.), Neue Juristenausbildung. Materialien, Neuwied 1970, gab ich meine abweichende Stellungnahme ab: „Reform und keine Revolution“, 77 - Beispiele für neue Lehrveranstaltungen, $94 \mathrm{f}$.

40 In Gerd Kadelbach (Hg.), Wissenschaft und Gesellschaft 1967, 213 und sodann Rechtswissenschaft 1968.

41 Ich hatte damals eine gegen ihn gerichtete Abhandlung „Das Recht am Gewerbebetrieb und das Recht auf Gewalt" niedergeschrieben, in dem ich die Rechtfertigung der Gewalt angriff. Die Veröffentlichung unterließ ich wohl deshalb, weil ich auf Wiethölter als Bundesgenossen in Sachen Einphasige Juristenausbildung nicht verzichten wollte. 
sitzender der Präsident des Braunschweiger Oberlandesgerichts Rudolf Wassermann war, der den Sammelband „Erziehung zum Establishment“ herausgab. In Frankfurt wurde Wiethölter Vizepräsident der Universität, Präsident war sein alter Mitkämpfer Denninger. Die Frankfurter bildeten auf dem Deutschen Juristentag in Düsseldorf 1972 die zwei Jahre zuvor von Wiethölter geforderte Arbeitsgruppe Justizforschung. ${ }^{42}$ Es war eine Verlegenheitslösung, denn gefragt war, wie die „Problematisierung“ des Rechts in der Lehre des geltenden Rechts umgesetzt werden sollte.

Der Vorschlag der ,einphasigen Ausbildung“ wurde vom Bundesgesetzgeber aufgegriffen und dementsprechend 1972 das Deutsche Richtergesetz geändert. Die Umsetzung blieb den Ländern überlassen, während ich auf die Errichtung einer Bundesmodellfakultät gehofft hatte. Allein eine solche mit Spitzenkräften besetzte und gegen Wegberufungen abgesicherte Modellfakultät hätte nach meinen Gießener Erfahrungen eine Erfolgschance gehabt. Wiethölters Konzeption eröffnete den 68ern die Möglichkeit, an der Planung teilzunehmen. Die Länder setzten dazu Kommissionen ein und errichteten neue Fakultäten, teils als Abspaltungen bestehender (Hamburg II), teils als neue in Bremen, Hannover, Trier oder Augsburg, oder griffen auf bereits bestehende zurück (Bielefeld, Konstanz). Wie weit die Kommissionsvorschläge dann doch wieder von den Fakultäten abgeändert wurden, weiß ich nicht. In der hessischen Kommission war ich ursprünglich als einziger Professor vorgesehen, doch wurde dann auf Druck der Frankfurter Studentenschaft Denninger (statt des von ihnen vorgeschlagenen Wiethölter) hinzugenommen, so dass damit die geschlossene Frankfurter Universitätsphalanx fast die Kommissionsmehrheit bildete - ich verzichtete daraufhin. ${ }^{43}$ Der Kommissionsentwurf scheiterte am Landtag, so dass die einphasige Ausbildung in Hessen nicht verwirklicht wurde. ${ }^{44}$

Die 68er wurden auf diese Weise von den Politikern föderalistisch aufgespalten und „ausgesessen“. Sie überwanden diese Zersplitterung nicht. Eine die Bonner Republik übergreifende Organisation brachten sie niemals zustande. Es blieb bei ihrem spektakulären Auftritt auf dem 48. Deutschen Juristentag in Bonn (1970). Der Bundesgesetzgeber beseitigte dann 1984 die einphasige Ausbildung, ohne dass sich dagegen Widerstand regte. Eine Zusammenstellung der Ergebnisse und eine Auswertung unterblieb, ebenso auch der Vergleich mit der traditionellen Ausbildung. ${ }^{45}$ Die weitere triste Geschichte der Juristenausbildung harrt noch immer des kritischen Chronisten.

VI. Für mich kam das Ende noch in einer anderen Beziehung schon früher, nämlich für meine rechtspolitische Betätigung für die SPD. ${ }^{46}$ Die spätere Bundesjustizministe-

42 Es referierten Spiros Simitis, Wiethölter, Manfred Weiß, Hubert Rottleuthner, Wolfgang Kaupen und Rüdiger Lautmann.

43 Der Entschluss ist mir dennoch nicht leicht gefallen. Ich scheute vor den zu erwartenden langwierigen Sitzungen zurück. Die mir ursprünglich zugedachte Rolle als einzigem Professor hatte der Justizminister ohnehin zerstört. Und an den Wettbewerbsföderalismus habe ich ohnehin zu keiner Zeit geglaubt.

44 Dafür war offensichtlich die Frankfurter Fakultät vorgesehen. Die auffällige Vermehrung der Lehrstühle hätte deren Teilung ermöglicht.

45 Die Justizministerkonferenz erwog noch einmal die Verwirklichung des einphasigen Modells, gab dies aber dann wieder auf. Auch der Druck, die Ausbildungen in Europa mit Hilfe des bachelors und des masters anzugleichen, hat daran nichts geändert - bis jetzt jedenfalls nicht.

46 Ich verweise insoweit auf meinen Sammelband Rechtsstaat (wie Anm. 10). 
rin der SPD, Däubler-Gmelin, entfernte mich aus dem Rechtspolitischen Ausschuss der Partei, ${ }^{47}$ „um für eine Frau Platz zu machen“. Ich wurde wieder Einzeltäter, ${ }^{48}$ schrieb noch, inzwischen Professor an der Fernuniversität in Hagen, 1985 ein „Eherecht", das ich in meiner Gießener Zeit konzipiert hatte. Mein „Jugendrecht" von 1990 sollte die Brücke zur DDR schlagen, wurde aber durch die Wiedervereinigung überholt. Die eine meiner beiden noch vorher gebildeten paritätisch deutsch-deutsch zusammengesetzten Kommissionen arbeitete den Entwurf eines Arbeitsvertragsgesetzes aus, den der Deutsche Juristentag aufgriff. Auf diesem sprach sich der Gutachter, mein bereits erwähnter ehemaliger Assistent, dagegen aus. Der Opportunist, der fellow traveller der Gewerkschaften, hatte die arbeitsrechtlich-politische Konstellation überhaupt nicht begriffen. Die zweite familienrechtliche Kommission kam zwar zu keinem Ergebnis, doch lag dies an den Meinungsverschiedenheiten der Westdeutschen.

Nun, den Gießener Traum von einem neuen Cluny hatte ich bereits 1977 ausgeträumt. Ich war maßlos enttäuscht, von dem Hessen ohne Zinn, dessen zündende Parole „Hessen voran“ das Signal für Reformen gewesen war, von der Fakultät, von der ausgebliebenen Studienreform, eigentlich von allem. Das Umfeld der Reform war gründlich zerstört. Ich setzte meine Hoffnung auf die neuen Medien und ging daher zur Fernuniversität in Hagen. Das Land Nordrhein-Westfalen versprach die erhoffte Reform. Sein bald eintretender finanzieller Kollaps zerstörte die Hoffnungen. Heute frage ich mich allerdings in der Rückschau, ob ich nicht doch besser in Gießen hätte bleiben sollen. In meinem letzten Seminar im WS 1976/77, in dem ich mich vertrat, lernte ich eine neue Studentengeneration kennen, mit der man hätte arbeiten können. Für die 68er galt dies nicht. Ich war der endlosen Suaden müde. Aber hätte ich nicht doch alles auf mich nehmen und in Gießen bleiben sollen? Offensichtlich fehlte mir zum Neuanfang der missionarische Eifer und Glaube oder schlicht das Durchhaltevermögen? Vielleicht habe ich mich doch zu wenig mit Cluny befasst.

VII. Ich komme nun zur Würdigung meiner Aussage und beginne mit dem Lebensalter. Bin ich nicht unglaubwürdig, weil ich als 1925 Geborener zu den Jahrgängen gehöre, die voll von der nationalsozialistischen Erziehung erfasst wurden ${ }^{49}$ Bin ich nicht damit automatisch Nazi geworden? Merkwürdig an diesem Argument ist, dass es den Generationenprotest und den individuellen Werdegang ignoriert - ist denn die

47 Ich hatte in diesem Gremium zunächst verschiedentlich über die juristische Ausbildungsreform vorgetragen. Es verkörperte für mich die ideale Verbindung von Rechtspolitik und Wissenschaft und bildete den Anlass für meinen Beitritt zur SPD.

48 Ich blieb noch zehn Jahre Karteileiche der SPD (schon um nicht den Eindruck der „beleidigten Leberwurst" zu erwecken) und trat dann bei der Wiedervereinigung Deutschlands aus, weil mir die Parteilinie unerträglich war. Bei der Beurteilung der Parteizugehörigkeit von Wissenschaftlern schien mir stets deren Unabhängigkeit das wesentlichste Kriterium zu sein. Heute vertrete ich die radikale Lösung: die Unabhängigkeit der Wissenschaftler nach außen klarzustellen und deshalb auf die Mitgliedschaft in einer Partei zu verzichten. Die Möglichkeit, politisch einzuwirken, wird dadurch keineswegs geringer.

49 Vgl. zum Folgenden Ramm, Justiz (wie Anm.1), 32 ff. 
Nationalerziehung als solche und damit auch die nationalsozialistische besser? ${ }^{50}$ Ich habe an anderer Stelle meine Entwicklung im „Dritten Reich“ geschildert ${ }^{51}$ und erspare mir deren Wiederholung. Ich denke jedenfalls nicht, dass mir eine braune Färbung meiner Aussage vorgeworfen werden kann. Sie ist indessen insoweit unvollständig, als sie nicht den Beginn der nationalsozialistischen Herrschaft erfasst, nicht die Legitimation der „Machtergreifung“ und den Kampf gegen die Weimarer Republik. ${ }^{52}$ Meine unmittelbare kritische Wahrnehmung der Ereignisse erstreckte sich auch auf die Universität. Ich konnte drei Semester vom SS 1942 bis zum SS 1943 studieren und dann wiederum vom WS 1945/46 bis zum WS 1946/47. Der Zeitzeuge konnte während dieser Zeit beobachten und die juristischen Fakultäten analysieren. Er war aber selbst vor und nach der bedingungslosen Kapitulation im Mai 1945 machtlos. Er war als Individuum Teil des deutschen Kollektivs und dessen Schicksal unterworfen.

VIII. Doch wie steht mit der Vergleichbarkeit des Bezugspunkts meiner Aussage, der Sondersituation Gießens als Reformfakultät? Es gab auch die Reformvorhaben von Konstanz (1966) und von Bielefeld (1969). Und sind nicht in eine weitergreifende geschichtliche Darstellung der Universitätslandschaft 1945 auch die Neugründungen der französischen Besatzungsmacht von Mainz und Saarbrücken sowie die Freie Universität (1949) und Bochum (1962) einzubeziehen? Endlich wären zum Vergleich in der Zeit auch die anderen Fakultäten heranzuziehen, und zwar ebenfalls in doppelter Perspektive: in der der Ordinarien und der der Studenten. Und natürlich gehören vor allem die 68er Neugründungen in Bremen, Hannover und Hamburg II sowie die anderen Neugründungen in Trier, Augsburg und in Regensburg in diesen Zusammenhang.

Ich bin damit schon von der Fakultät auf die Universität gesprungen und berühre damit einen wesentlichen Punkt. Die eigentliche Wirkungsstätte der 68er waren die Politikwissenschaft und die Soziologie. Die Juristen waren nur ein Nebenkriegsschauplatz. Aber dies galt ohnehin für Gießen allgemein. Es gehörte zum Einflussbereich von Frankfurt und wohl auch von Marburg. Auf die Gießener Universität traf jedenfalls die Charakterisierung „Tollhaus“ (so Günter Gillessen in der Frankfurter Allgemeinen Zeitung) generell nicht zu. ${ }^{53}$ Die Wahl des Konservativen Meimberg zum Präsidenten und die Integration der Weilburger Pädagogischen Hochschule verbunden

50 Es bedürfte hier einer Auseinandersetzung mit der Geschichte der deutschen Pädagogik. Ist der Zweifel an der individuellen Entwicklung ein solcher an der Familienerziehung? Wird der kollektivistischen Erziehung unterstellt, dass sie dem Kind besser gerecht werde? Der französische Frühsozialist Charles Fourier hat dies vollendet dargetan, vgl. dazu Thilo Ramm, Die großen Sozialisten als Rechts- und Sozialphilosophen Bd. 1, Stuttgart 1955, 358. Und die ganze Kinderschutzgesetzgebung war natürlich ein einziger Angriff auf die Unzulänglichkeit der Familienerziehung und bereitete um 1900 den Umschwung vor, vgl. dazu Thilo Ramm, Jugendrecht, München 1990, 58 ff. Der Nationalsozialismus profitierte davon (S. $78 \mathrm{ff}$.) und fügte die militaristische Komponente als die bestimmende hinzu.

51 Vgl. Ramm (wie Anm. 10), LXVII f., und Ramm, Justiz (wie Anm. 1), 32 ff.

52 Die beste Zusammenfassung der damaligen Perspektive scheint mir Fritz Sterns Essay „Der Nationalsozialismus als Versuchung“, in: Ders., „Der Traum vom Frieden und die Versuchung der Macht. Deutsche Geschichte im 20. Jahrhundert“, Erw. Neuaufl. Berlin 1999 [zuerst 1988], 169-217 zu sein.

53 Ich denke, dies ist auf die Rolle der Landwirte und Veterinärmediziner zurückzuführen. Hier wäre die Analyse der einzelnen Fakultäten von Interesse. 
mit der Höherstufung der Assistenten wirkten langfristig als Befriedung. Allgemein ging allerdings der bisherige staatliche Rückhalt verloren. Die politische Einflussnahme durch den Kultusminister von Friedeburg war eine Parteinahme. Sie sollte indessen nicht überbewertet werden. Ein verwaltungserfahrener Dekan parierte sie mit bürokratischer Langsamkeit.

IX. Ich beschließe meine Darstellung als Zeitzeuge mit einer Frage, die ich an mich bei den Verhandlungen über meine Teilnahme an dieser Vortragsreihe gerichtet habe: Bin ich nicht eigentlich selbst ein 68er gewesen? Roderich Wahsner hat mich, auch nach meiner Distanzierung von Wolfgang Däubler, nach wie vor der Linken zugezählt, ${ }^{54}$ und dies entsprach auch wohl der Meinung meiner Fachgenossen seit meiner Habilitation und meinem Angriff auf Nipperdey und das BAG. Zwei italienische Kollegen, Lorenzo Gaeta und Gaetano Vardaro, charakterisierten mich 1989 in ihrer Einleitung zur italienischen Edition meiner arbeitsrechtlichen Schriften als ,inneren Emigranten" und ordneten mich dementsprechend in die Arbeitsrechtswissenschaft vor zwanzig Jahren ein. ${ }^{55}$ Ich habe demgegenüber zur Auswahl und Entstehungsgeschichte meiner Schriften in einem eigenen Vorwort ausführlich Stellung genommen, ${ }^{56}$ das dann die Grundlage meiner späteren „Bestandsaufnahme“"57 gebildet hat. Blicke ich jetzt auf meinen wissenschaftlichen Werdegang zurück, so sehe ich in ihm den Protest und den Versuch, eine vom ,Zeitgeist“ unabhängige wissenschaftliche Position zu begründen, die die politische Wahlfreiheit einschloss. Ich war Ketzer, wissenschaftlicher und politischer, und bezahlte dies mit dem Verlust meiner juristischen Karriere. ${ }^{58}$ Doch wie hätte ich mich eigentlich später, 1968, ohne den Gießener Ruf, verhalten, der die Chance zur eigenen Gestaltung eröffnete. ${ }^{59}$ Der Freiburger Nichtordinarius empfand seine Zurücksetzung im Berufungskarussell als ungerecht - je länger sie

54 DuR 6 (1978), 434. In diesem Heft wurde ebenfalls Kritik an Däubler geübt, der replizierte (S. 371, 382). Vgl. auch Roderich Wahsner, Blätter für deutsche und internationale Politik 22 (1977), 107. Wahrscheinlich hat meine Einordnung veranlasst, dass ich als Opfer der Restauration des kapitalistischen Arbeitsrechts angesehen wurde, vgl. dazu Ders., Das Arbeitsrechtskartell - Die Restauration des kapitalistischen Arbeitsrechts in Westdeutschland nach 1945, KJ 7 (1974), 372.

55 In ihrer Einleitung zur Edition Per una storia della costituzione del lavoro tedesca Bd. 31 der Biblioteca di Paolo Grossi 1989: ,,, un passato che non passa', Thilo Ramm e la dottrina giuslavoristica tedesca“", 1-19.

56 S. 21-34.

57 Ich bezeichnete sie als „bibliographie annotée“ und stellte sie dem Band Rechtsstaat (wie Anm. 10) voran.

58 Im historischen Rückblick meine ich allerdings, es hätte auch anders ausgehen können, wenn nicht der Hauptkassierer der IG Metall mit seinem Votum die Rücknahme der Verfassungsbeschwerde gegen das Urteil des BAG im schleswig-holsteinischen Metallarbeiterstreik veranlasst hätte. Doch die radikalste deutsche Gewerkschaft blieb in der Tradition der Weimarer Republik, die eigene Position nicht mit aller Entschiedenheit zu verteidigen.

59 Übrigens war ich von einer Trotzreaktion, den Ruf abzulehnen, gar nicht so weit entfernt. Die Honorierung meiner Arbeiten über den Sozialismus durch die Politikwissenschaftler hätte ich durchaus akzeptiert, wenn sie früher erfolgt gewesen wäre. Inzwischen hatte ich für die Rechtswissenschaft optiert. Die Rufannahme erfolgte sub specie der Wiedererrichtung der Gießener juristischen Fakultät. 
andauerte. Wäre dies nicht ein hinreichender Grund zur Empörung gewesen ${ }^{60}$ Natürlich gehört diese Fragestellung zur ,virtuellen Geschichtsschreibung“.61 Doch leitet sie zur Würdigung der 68er in heutiger Perspektive über. Mit ihr streift der Zeitzeuge die Toga des Zeithistorikers über.

\section{B. Vierzig Jahre danach}

I. Nach vierzig Jahren hat sich der Pulverdampf über das Geschehen verzogen. Aber hat mit der zeitlichen Distanz die Historisierung dieser Vorgänge begonnen? Ich vermisse ihre Zusammenfassung und Analyse. Wer hat als Zeitzeuge berichtet, und wie erinnern sich die Zeitzeugen an ihre individuellen Erlebnisse - als Überstehen von Gefahr wie der „,alte Herr" an seine erste Mensur als Burschenschaftler oder der Soldat an den Nahkampf, und in die Erinnerung mischt sich der Triumph über die Überwindung der damaligen Ordnung. ${ }^{62}$ Oder gilt die Erinnerung etwa der Selbstpreisgabe des Individuums, an sein Aufgehen in ein Kollektiv? Müssen wir historische Parallelen ziehen: zum Verhältnis Intellektueller zum Kommunismus oder zu Hitlers „Machtübernahme"?

Historisieren heißt, sich von der früheren Gegenwart zu lösen und damit den Bericht über die unreflektierte Beteiligung am Geschehen durch dessen kritische Überprüfung zu ersetzen. Daher ist sie in der Regel Sache der nächstfolgenden Generation. ${ }^{63}$ Sie hat zu rekonstruieren, ,wie es wirklich gewesen ist“". Ist dies aber bislang geschehen? Wie steht es mit der Quellenkritik durch die unparteiischen Historiker? Besteht wenigstens Klarheit über die Maßstäbe, mit denen die Ereignisse gemessen werden können? Und wie sind die historischen Vorgänge retrospektiv zu koordinieren? Fragen über Fragen, die es zu beantworten gilt. Immerhin besteht offenbar das Bedürfnis, sie zu beantworten und die Vorgänge zu analysieren, was auch die Veranstaltung dieser Tagung beweist.

Die Aufgabe, als Zeithistoriker die Geschichte der 68er zu schreiben, kann ich freilich nicht bewältigen, um so weniger als dies nur im Kontext der allgemeinen Geschichte, nicht nur der westdeutschen, sondern ebenso der ostdeutschen und der europäischen und amerikanischen geschehen müsste. Warnen würde ich ebenso vor der Überbewertung des Geschehens an den deutschen Universitäten. Im Vergleich zur politischen Klasse war der Durchschnittsbürger desinteressiert. Sehr viel wichtiger wurde für ihn die Bildung einer neuen politischen Partei durch die 68er. Die „Grünen“ gehören daher zu deren Darstellung. Ich erinnere mich noch an das Wort des hessi-

60 Ich war dem bei der Darstellung Babeufs in Bd. 1 meiner „großen Sozialisten“ (wie Anm. 52) nachgegangen.

61 So der Titel des seit 1999 auf deutsch vorliegenden Sammelbandes von Niall Ferguson (Hg.), Virtuelle Geschichte, Darmstadt 1999.

62 Im „Universum“, der Zeitschrift der Gießener Universität (14.7.2007), spricht der frühere Wortführer Brinkmann sogar nur von der „Aufmüpfigkeit“, die er allerdings als bleibende Errungenschaft ansieht.

63 Sie ist auch eine Lösung von der personellen Identität. Wahsner (wie Anm. 56) hat die Kontinuität der damaligen Arbeitsrechtswissenschaft nach dem Zusammenbruch herausgestellt und als „Arbeitsrechtskartell“" gewertet. 
schen Ministerpräsidenten Holger Börner über den Umgang mit diesen: „Mit der Dachlatte drauf schlagen“. Er tat es nicht, sondern koalierte, vom Machtinteresse seiner Partei getrieben, mit diesen. Die Vereidigung des neuen Ministers Joschka Fischers in Turnschuhen zeigt dessen Verachtung der Anstandsformen der parlamentarischen Demokratie. Nichtsdestotrotz, die Grünen lernten durch die Machtbeteiligung den Amtsverstand. Aber dies ist ein Thema für sich.

Mir fällt ferner auf, dass nur von einem Gedenkjahr, von 1968, ausgegangen wird. Damit werden aber die Akzente einseitig gesetzt. 1977 ist zum zweiten Gedenkjahr geworden. ${ }^{64}$ Von den 68ern hat sich eine terroristische Bewegung, die „Rote Armee Fraktion", abgespalten, die Mord und Geiselnahme praktiziert hat. Ihr Terror und politischer Mord ist indessen von der Bejahung der Gewalt durch die 68er nicht abzutrennen. Die 68er-Bewegung bildet eine Einheit durch die Gewalt und hat ein Klima der Bedrohung geschaffen. ${ }^{65}$ Sie hat Gewalt als ihr Recht beansprucht und ist dann doch der stärkeren Staatsgewalt erlegen, die sich mit dem „Radikalenerlass“ Willy Brandts erwehrte. ${ }^{66}$ Das Ende der 68er ist der inszenierte kollektive Selbstmord ihrer Führer in Stammheim, der als Mord dem Staat zugeschoben werden sollte - womit der moralische Tiefstand der Bewegung bestätigt wurde. Dass die 68er dieser Inszenierung weithin Glauben schenkten, zeugt ebenso wie das Fehlen jeglicher Distanzierung von der „Roten Armee Fraktion“ von der Einheit der 68er-Bewegung. ${ }^{67}$

II. War die 68er-Bewegung eine Revolution? Der Begriff Revolution verweist auf den tiefen Einschnitt, auf die dauerhafte grundlegende Veränderung. In der Weimarer Republik ist eingehend erörtert worden, ob er für die Vorgänge im Jahr 1918 verwandt werden kann. Dies ist damals fast einhellig abgelehnt worden, und dies zu recht. Der Kieler Matrosenaufstand führte zwar zur Machtergreifung der Räte und ersetzte die Monarchie durch die parlamentarische Demokratie. Es blieb aber bei einer partiellen Veränderung der Machtverhältnisse. Die Länder und das Berufsbeamtentum wurden nicht angetastet und das Amt des Reichspräsidenten wurde zum „Ersatzkaisertum“. Die politische Macht, die Ausarbeitung der Verfassung wurde den Parteien überantwortet. Der Aufwertung der bisherigen politischen Klasse entsprach die le-

64 Vgl. dazu das von Hans-Georg Golz herausgegebene Heft 40/41 des Jg. 2007 von Politik und Zeitgeschichte. Es kontrastiert sehr zur positiven Wertung Ludwig Watzals des Sammelhefts 1968 APuZ 2008 Heft 14/15.

65 Vgl. Kurt Breucker, Der deutsche Herbst 1977 und die „RAF“ - Erinnerungen eines Zeitzeugen, in: Thomas Vormbaum (Hg.), Jahrbuch der Juristischen Zeitgeschichte 9 (2007/08), 306.Er setzt zwar die 68er nicht mit den Terroristen „einfach gleich“, bringt aber selbst Beispiele für deren Gewaltausübung (Joschka Fischer) und erwähnt das Selbstverständnis der „RAF“, die in der studentischen Protestbewegung ihre eigene Vorgeschichte gesehen habe.

66 Seine Haltung verdiente eine besondere Analyse. Bestimmend für sie mag einerseits die Erinnerung an die eigene Jugend gewesen sein und andererseits die Abwehrnotwendigkeit als Kanzler. Bemerkenswert war der Versuch, mit der Ernennung Werner Maihofers, des Rektors der Saarbrücker Universität, einen Brückenschlag zu versuchen. Er blieb jedoch erfolglos.

67 Wer sich als 68er darauf beruft, dass die „Rote Armee Fraktion“ nur eine verschwindende Minderheit gewesen sei, die einen getrennten Weg gegangen sei, muss sich die Frage gefallen lassen, warum er dann nicht diese Trennung offen bekundet hat. Wie weit haben sie sich eigentlich von der Vätergeneration unterschieden, der sie vorwarfen, nicht der nationalsozialistischen Herrschaft widerstanden zu haben? 
diglich partielle Veränderung des politischen Bewusstseins. Das „Vernunftrepublikanertum" reichte als Fundament der neuen Ordnung nicht aus. Das Ergebnis war, dass die durch die Oktobergesetze von 1918 bereits in Umbildung begriffene Staatsmacht schwer erschüttert war und sich nicht zu regenerieren vermochte.

Die 68er-Bewegung hat noch weniger erreicht. Sie hat die nach der bedingungslosen Kapitulation ausgebildete neue Herrschaftsordnung, das „Establishment“, unangetastet gelassen: und dies in beiden deutschen Teilstaaten. Sie hat in Westdeutschland weder die parlamentarische Demokratie noch den Föderalismus in Frage gestellt noch die Aufhebung der deutschen Teilung gefordert. Bei ihrem „Marsch durch die Institutionen“ hat sie ihr eigenes linkes „Establishment“ gebildet, das sich dann letztendlich in das alte integrierte. Es war dies ein wechselseitiger Prozess. Sicherlich haben die Menschen die Institutionen verändert, aber ihre Veränderung durch die Institutionen scheint mir gewichtiger zu sein. Was ist davon geblieben? Die Vermehrung der Parteien und mit ihr der Koalitionsmöglichkeiten bei der Regierungsbildung. Und im Übrigen ist offensichtlich die personelle Integration über die Gerichtsbarkeit erfolgt.

Aber war sie wenigstens eine Kulturrevolution? Haben, wie behauptet wird, die 68er im Sexualbereich einen befreienden Durchbruch vollzogen? Sicherlich haben sie die sexuelle Freiheit in Anspruch genommen. Deren tatsächliche und bestimmende Basis war indessen die Perfektionierung der Empfängnisverhütung durch die „Pille“. Wesentlich aber war die Ablehnung der persönlichen Bindung durch die 68er. „Wer zweimal mit derselben pennt, gehört schon zum Establishment.“ Die Frau blieb Objekt. ${ }^{68}$ Die 68er praktizierten in ihrer Bewegung die Gleichberechtigung keineswegs selbst, sondern verwiesen die Frau auf untergeordnete Tätigkeiten.

Und die Universität? Das Angriffsziel war die Hierarchie, die Stichworte hießen Demokratisierung und Mitbestimmung. Inhalte und Ergebnisse sind umstritten. Die Individualherrschaft des Ordinarius über den Assistenten ${ }^{69}$ wurde in Frage gestellt. Aber hat sie sich nicht zwangsläufig regeneriert durch die Angewiesenheit auf den Ordinarius für das spätere berufliche Fortkommen? Sicherlich hat der Ansturm des Kollektivismus eine Reinigung der stickigen Luft bewirkt - aber auf wie lange? Das damalige Geschehen lässt sich wohl in zwei Feststellungen zusammenfassen. Die eine betrifft die Reaktion der angegriffenen Ordinarien, die allerdings unterschiedlich war. Sie haben sich der „Umfunktionierung“ ihrer Vorlesungen teils widersetzt - und dabei in Erinnerung an den nationalsozialistischen Angriff auf die Wissenschaftsfreiheit „Flagge" zu zeigen versucht. Teils riefen sie die Polizei zur Hilfe. Teils reagierten sie passiv, indem sie die Vorlesung ausfallen ließen. Die „Scheißliberalen“ ließen sich auf inhaltliche Diskussionen ein. Die zweite Feststellung betrifft die Gruppenbildung. Auf das „Marburger Manifest“ (1968) folgte zunächst als Reaktion die Gründung der „Bundes demokratischer Wissenschaft“ (1968), gegen die sich wiederum der ungleich mächtigere „Bund Freiheit der Wissenschaft“ (1970) bildete. Doch es bleibt die Fra-

68 Vgl. auch Gretchen Dutschke, Rudi Dutschke: wir hatten ein barbarisches, schönes Leben eine Biographie, München 1998, 81: „Frauen galten als Zubehör, das nach Belieben weggelegt werden konnte", dazu auch S. 83.

69 Ich gestehe ein, hierüber nicht mitreden zu können. Ich bin niemals wissenschaftlicher Assistent gewesen, sondern genoss als Stipendiat der Deutschen Forschungsgemeinschaft die Freiheit der Forschung. 
ge, warum eigentlich nicht die 68er eine eigene länderübergreifende Organisation schufen.

III. Die 68 er blieben beim Protest stehen. Die westdeutschen Studenten ${ }^{70}$ waren eine Gruppe, die isoliert blieb. Die Deutung als Generationenprotest erklärt die spätere Geschichte der 68er jedenfalls zum Teil als altersbedingten Wandel. Der aufbegehrende Jugendliche ${ }^{71}$ wird klüger, bis er schließlich als Konservativer endet, wie etwa Otto Schily, oder gar als restlos umgekippter Rechtsradikaler, wie Horst Mahler. Der durchschnittliche Alt-68er erinnert sich heute seiner Vergangenheit als Jugendsünde, auf die er natürlich ein bisschen stolz ist, obschon (oder weil?) er sich inzwischen in die politische Klasse eingefügt hat. ${ }^{72}$ Aber er scheint sich nicht zu seiner Vergangenheit bekennen zu wollen. Dies wäre wohl auch karrierefeindlich gewesen. ${ }^{73}$

Der Protest war ein gewaltsamer, aber kein elementarer Akt, kein Akt der Befreiung, wie er nach dem Zusammenbruch des ,totalen“ Staates hätte erwartet werden können. Dafür kam er zwanzig Jahre zu spät und fügt sich somit in Helmuth Plessners Deutung der deutschen Geschichte als der ,zu spät gekommenen Nation“ ein. Er respektierte letzthin trotz aller Empörung ${ }^{74}$ die bestehenden Machtverhältnisse, die durch die bedingungslose Kapitulation geschaffene fremdbestimmte Ordnung, die die Deutschen hinnahmen und weiter ausfüllten.

Was hätten die 68er aber eigentlich tun können? Die nationale Einheit und die im Grundgesetz fehlende direkt-demokratische Komponente, die verfassungsgebende Gewalt des Volkes einzufordern, hätte die Revolution bedeutet. Der Bruch mit dem nationalsozialistischen Recht, es als solches außer Kraft zu setzen, wäre nach zwanzig Jahren restaurativer Politik, nach der Vermengung von Altem und Neuem wohl praktisch undurchführbar gewesen, aber der Schnitt hätte doch in der Theorie durchgeführt werden können. Und dies hätte die Selbstreinigung der Rechtswissenschaft erleichtert. ${ }^{75}$

Für die spezifisch juristischen Fragen des Zivilrechts stand den 68ern Bernd Rüthers’ Habilitationsschrift „Die unbegrenzte Auslegung. Zum Wandel der Privat-

70 Die DDR ist davon unberührt geblieben (vgl. hierzu die Diskussion um die Tagebucheintragungen des Historikers Zwahr, dazu Hans-Georg Golz [Hg.], APuZ 20/2008, 27), was von der Stärke des Abwehrmechanismus eines totalen Systems zeugt. Die Gleichzeitigkeit anderer nationaler Proteste bedeutet nicht, dass es sich um eine internationale Bewegung gehandelt hat.

71 Bekanntestes Beispiel für den zeitgeistbedingten Wandel des jugendlichen Anführers ist der „Blechtrommler“ Günter Grass. Unterhalb des praeceptor Germaniae hat Franz Degenhardt in seinem Lied über „Horsti Schmantoff“ die Karriere des stets angepassten opportunistischen Mitläufers vom HJ-Führer bis zum Häuptling eines Negerstamms geschildert.

72 Der Vergleich mit dem Burschenschaftler liegt nahe. Als ,alter Herr“ gehört er den „Philistern" an, pflegt aber seine Erinnerungen.

73 In diesem Rahmen sollte ein Blick auf das Gedenken an Abendroth und Ridder geworfen werden. Für Abendroth ist eine Gesamtausgabe im Werden. Für Ridder scheint sie immerhin vorbereitet zu sein.

74 Ich denke heute, dass die Erinnerung an diese die bleibende positive Erinnerung an die 68er ist. Die Erhebung gegen die bestehenden Machtverhältnisse setzte bisher gebundene Kräfte frei. Der Historiker hätte diese zu registrieren, ohne sie den 68ern direkt zuzurechnen.

75 Sie war allerdings in doppelter Weise schwierig. Der Nationalsozialismus verwirklichte in der Anfangsphase steckengebliebene Reformen der Weimarer Republik und stand andererseits am Ende einer Entwicklung, die durch den aufgeklärten Absolutismus und den Glauben an den Staat geprägt war. 
rechtsordnung im Nationalsozialismus“ (1968) zur Verfügung. Noch vor ihrer Veröffentlichung war Rüthers nach Berlin an die „Freie Universität“ auf einen rechtssoziologischen Lehrstuhl berufen worden. ${ }^{76}$ Den verfassungsrechtlichen Ansatz zur Umgestaltung des Eherechts hatte ich mit meinem Aufsatz „Gleichberechtigung und Hausfrauenehe“ (1968) und „Grundgesetz und Eherecht“ (1972) aufgezeigt. Den Weg, die nationalsozialistische Machtordnung aufzuarbeiten, hatte der ebenfalls in Berlin lehrende Ernst Fraenkel eröffnet, dessen Buch über den „Doppelstaat“ 1974 endlich ins Deutsche übersetzt wurde. Dem Remigranten selbst ist aber übel mitgespielt worden.

Was hätten die 68er tun können? Eine der Chancen zur Umgestaltung war die Einführung des Rechtskundeunterrichts an den höheren Schulen. Sie hätten die Assistenten übernehmen können, aber, ich erinnere mich an Gießen, dazu waren sie zu fein sie wollten an den Universitäten bleiben und überließen diese Aufgabe lieber altgedienten Praktikern. ${ }^{77}$ Eine zweite Chance eröffnete das „Fernstudium im Medienverbund“. Das „Deutsche Institut für Fernstudien“ in Tübingen hatte im Rahmen seiner wissenschaftlichen Orientierungsveranstaltungen auch das „Recht“ behandelt. Auch diese Chance ergriffen die 68 er nicht. ${ }^{78}$

Einfacher schien die Auseinandersetzung mit den Personen, die sich nach 1945 nicht zu ihrer Verantwortung bekannten. Damit konnten die 68er an das Anliegen der missglückten Entnazifizierung anknüpfen. Sie sind gescheitert, weil sie von der verständlichen Empörung über den „Unrechtsstaat“79 ausgingen, dessen Verbrechertum aufgedeckt worden war. Sie sind jedoch weder der Situation des ,totalen Staats“ noch der des Individuums in diesem gerecht geworden. Den 68ern ist als „Wohlstandskindern“ in einem Rechtsstaat das Gefühl für das Leben in einem „totalen“ Staat der Konzentrationslager und der Geheimen Staatspolizei abgegangen. Ihnen haben als Bewertungskriterien die Angst, die Furcht vor unberechenbaren Aktionen, vor Willkür bei

76 Rüthers hat auf einer dreißig Jahre später veranstalteten Tagung über „,1968 und die Folgen“ berichtet (veröffentlicht im Internet). Er verweist auf Günter Gillessens zeitgenössischen Leitartikel in der Frankfurter Allgemeinen Zeitung „Die Universität als Tollhaus“. Gleichzeitig mit ihm wurde Uwe Wesel berufen, der ab 1969 als Vizepräsident der FU fungierte.

77 Es konnte auf Radbruchs Vorschläge zum Rechtskundeunterricht zurückgegriffen werden. Rudolf Gerhardt gab damals die Zeitschrift „Recht und Gesellschaft“ heraus, die dann nach zwei Jahren vom C. H. Beck Verlag eingestellt wurde. Meine Frau sprang damals in Gießen in die Bresche. Sie entwickelte ein Curriculum und erteilte Unterricht. Von der Rechtskunde ließen sich Brücken zur Gemeinschaftskunde schlagen, die von den Politikwissenschaftlern eingeführt worden war.

78 Einen Planungsentwurf fertigte meine Frau im Auftrag des Instituts an. Vgl. Renate Ramm, Das juristische Studium im Medienverbund, München 1971.

79 Dieser Begriff bezieht sich auf die Bewertung nach den Normen. „Schurken“- oder „Verbrecherstaat" stellt auf die Personen ab. Beide Perspektiven schließen sich nicht aus, doch reicht die zweite noch weiter: Verbrecher ist auch, wer aufgrund seiner Stellung die Rechtspflicht zum Handeln besaß und ihr nicht nachkam. 
der Ausübung der Herrschaft ${ }^{80}$ und der Verlust individueller Verantwortung gefehlt. Die 68er haben sich mit Klischees begnügt, mit der Anknüpfung an formale Kriterien wie Mitgliedschaften und Zitate. Sie haben es unterlassen, sich in die frühere Situation der von ihnen Angegriffenen zu versetzen und sich die Frage vorzulegen, die vor jeder historischen Verurteilung steht: Wie hätte ich mich damals selbst verhalten: anders, und wie, oder genauso? Sie haben ferner nicht den Rahmen bestimmt, in dem sie ihr Urteil fällten: weder den objektiven, den faktischen, den die beiden Notverordnungen von 1933 mit der Einrichtung von Konzentrationslagern setzten, noch den rechtlichen mit dem Ermächtigungsgesetz und dem „Staatsnotstand“ anlässlich der RöhmMorde noch den subjektiven: In welcher Situation sich der Einzelne befunden hat: Wie alt war er, hatte er seine Karriere noch vor sich oder war er bereits etabliert? Über welchen Handlungsspielraum verfügte er? Mit solchen Fragen hätte jedenfalls das deutsche „Establishment" ${ }^{\text {"81 }}$ aufgebrochen werden können.

Den 68ern fehlte nach dem Angriff auf die Notstandsgesetzgebung der realpolitische Ansatz. Sie hätten zumindest den Anschluss an die internationale Menschenrechtsentwicklung herstellen können. 1972 traten beide deutsche Teilstaaten in die Vereinten Nationen ein und ratifizierten deren Internationale Pakte über bürgerliche und politische Rechte und über wirtschaftliche, soziale und kulturelle Rechte. Die Pakte waren das juristische Erbe einer Generation, die den Zweiten Weltkrieg erlebt und 1945 die Menschenrechte proklamiert hatte ${ }^{82}$ - nur fehlten dabei die Deutschen, unter denen der 20. Juli 1944 eine unersetzbare Lücke gerissen hatte. Die Menschenrechte auf Arbeit, auf Gesundheit, auf Bildung und auf Existenz entsprachen doch den Zielset-

80 Franz L. Neumann hat hierüber 1954 einen brillanten Vortrag „Angst und Politik“ gehalten (auch in: Alfons Söllner [Hg.], Wirtschaft, Staat, Demokratie. Aufsätze 1930-1954 Frankfurt 1978, 424 ff.), der sich auf die 1941 von Roosevelt verkündete vierte Freiheit „freedom from fear" bezog. Der Rechtsstaat ist die dagegen entwickelte institutionelle Sicherung. Doch gibt es nicht auch eine im kollektiven Unterbewusstsein tief verwurzelte Angst, die aus schrecklichen Erlebnissen wie dem Dreißigjährigen Krieg oder dem letzten Kriegsjahr des Zweiten Weltkriegs herrührt?

81 Bei seiner Ausbildung war die Entnazifizierung durch die alliierten Militärregierungen und die spätere Reintegration der von dieser Betroffenen wohl der bestimmende Faktor. Als ich 1953 habilitiert wurde, war die juristische Fakultät in Freiburg eine Gruppe, in der Remigranten, Altnazis, Deutschnationale oder Max-Planck-Juristen nebeneinander saßen - geduckt unter das neue Herrschaftssystem, zusammengehalten durch die Sorge um die eigene Existenz (Die Angst in der NS-Zeit, vgl. weitergreifend Franz L. Neumann [wie Anm. 82], hatte sich in eine allgemeine Furcht verwandelt) und durch das unpolitische Weitermachen in ihrem kleinen überschaubaren Forschungsbereich. Aber es fänden sich auch Allianzen. So beteiligte sich Franz L. Neumann an Nipperdeys Großprojekt „Die Grundrechte“ als Herausgeber.

82 Auf die Frage nach ihrer unmittelbaren Verbindlichkeit für die Bonner Republik und nunmehr die Bundesrepublik Deutschland bin ich erst vor einiger Zeit gestoßen, vgl. meine Aufsätze „Sozialstaatsprinzip und Recht auf Gesundheit“, in: VSSR 2008, 204 ff. und „Von der Arbeiterversicherung zum Sozialgesetzbuch“, in: Thomas Vormbaum (Hg.), Jahrbuch der Juristischen Zeitgeschichte 9 (2007/08), 87 ff. 
zungen des 68er und hätten nicht nur die deutsche Teilung in Frage stellen, sondern auch den Schritt über Deutschland tun können. ${ }^{83}$

Dieselbe Frage erstreckt sich auch auf die deutsche Situation. Warum haben die 68er keine Kontinuität gesucht, warum haben sie nicht die Verbindung zu denjenigen hergestellt, die sich in ihrer Forschung gegen den Nationalsozialismus gewandt hatten: Eugen Kogon, Dolf Sternberger, Ralf Dahrendorf, Karl Dietrich Bracher, Theodor Eschenburg? Weil sie jedwede Hierarchie und Autorität zerstören wollten? Es bot sich doch an, an Georg Picht und Ralf Dahrendorf mit ihren Forderungen eines „Rechts auf Bildung“ anzuknüpfen und den Föderalismus aufzubrechen. Oder die 68er hätten Ridder und Abendroth zur politischen Führung gewinnen können? Sie blieben indessen ihren eigenen Führern treu, auch als sich diese aus Enttäuschung über den ausbleibenden Erfolg des Terrors als politischen Mittels bedienten. Eine andere Frage ist, inwieweit nicht andere damalige Meinungsführer ihnen Hilfe und Förderung angedeihen ließen. Sie ist Heinrich Böll gestellt worden. Hans Magnus Enzensberger „Freisprüche. Revolutionäre vor Gericht“ (1970) ist sicherlich als Ermutigung gedacht gewesen.

IV. Was war also die westdeutsche 68er-Bewegung? Ich würde sie als Emeute charakterisieren, deren Wirkung kurz bemessen ist, ${ }^{84}$ und den Vergleich zum WartburgFest der Studenten von 1817, zum Matrosenaufstand von 1918 oder zum 17. Juni 1953 ziehen. Der Begriff verweist auf die Gemeinsamkeit im Subjektiven und auf die Begrenzung des Erfolgs durch die objektive Situation, die von der Stabilität der angegriffenen Ordnung abhing: 1817 von der restaurierten Monarchie, 1918 vom Beamtenstaat und vom Parlamentarismus und 1953 von den russischen Panzern. Die Bonner Republik bestand ebenfalls ihre Bewährungsprobe, obschon sicherlich nicht glanzvoll, und brauchte nicht die Hilfe der amerikanischen Besatzungsmacht in Anspruch zu nehmen. Die Emotionalität der Bereitschaft zur Gewalt fordert wiederum den historischen Vergleich heraus, ${ }^{85} \mathrm{zu}$ dem mir das Musterbeispiel sinnloser militärischer Gewalt, der Sturm auf Langemarck von 1914 einfällt.

Mit dem Begriff der Emeute, des Aufruhrs wird leicht ein negatives, ein abwertendes Urteil verbunden. Es gründet sich auf das Fehlen klarer rationaler Zielsetzungen, ${ }^{86}$ die durch Gefühle ersetzt werden. Die 68er können sich nicht darauf berufen,

83 Die Internationalität der 68er-Bewegung zu untersuchen, bildet eine weitere reizvolle Aufgabe. Eine Rolle dabei spielt das 3. Internationale Russell-Tribunal „Zur Situation der Menschenrechte in der Bundesrepublik Deutschland“, 4 Bde., Berlin 1978/79.

84 Ich erinnere mich daran, dass mich mein Ex-Habilitand (vgl. dazu weiter oben), der inzwischen wohl etablierter Richter am Bundesarbeitsgericht geworden war, mich nach Jahren freudig begrüßte, als ob nie etwas geschehen gewesen sei und nicht verstand, dass ich zumindest ein Wort der Entschuldigung oder zumindest Erklärung erwartete. Die emotionale kollektive Woge war verrauscht und hatte nichts hinterlassen. Diese Reaktion entsprach genau dem Verhalten der Nazis nach 1945.

85 Oder ist dies nicht alles viel zu hoch angesetzt? In der Wohlstandsgesellschaft gibt es als Reaktion auf die geordnete Langeweile doch den Ausbruch in das kollektive Rowdytum. Ich neige dazu, die 68er auch zumindest teilweise in diesen Zusammenhang einzuordnen.

$86 \mathrm{Zu}$ recht beklagt Karl Otten, Der verhaltensgestörte Tausendfüßler, in: Bilanz (wie Anm. 2), 413, dass eine Sammlung der damaligen Wandsprüche fehlt. Er zitiert drei: „Die Uni ist zu klein/Zingel raus - Studenten rein“ (Marburg), „Lieben ohne Last/Abtreibung ohne Knast“"(Heidelberg) und „Dem Volk verhilft zur Freiheit nur/die Arbeiterdiktatur“" (Marburg). 
ein allgemeines Bewusstsein repräsentiert zu haben. Dies hat sich vielmehr gegen sie gerichtet. Wie jede kollektive Bewegung haben sie einen frischen Wind hereingebracht und die bisherige stickige Luft verdrängt. Aber es war kein auf die Dauer reinigendes Gewitter. Zu untersuchen wäre die lokale Begrenzung, und hier fehlen die historischen Analysen der Neugründungen von Bremen, Hannover oder Hamburg II. Die Durchführung ihres einphasigen Ausbildungsplans ${ }^{87}$ reicht nicht aus. Die Geschichte dieser Fakultäten bleibt ein Forschungsdesideratum, wie natürlich zu Vergleichszwecken auch die Geschichte der anderen Fakultäten, die die einphasige Ausbildung durchführten. $\mathrm{Zu}$ denken gibt sicher die Geschichte der Freien Universität Berlins. Bernd Rüthers erwähnt, dass in dieser Zeit sämtliche elf Berufenen die Fakultät wieder verließen. Aber wie hat sich eigentlich Frankfurt entwickelt, nachdem sich die Hoffnung auf die Teilung der Fakultät und die Durchführung der einphasigen Ausbildung an Frankfurt II zerschlagen hatte?

Hat sich durch die 68er die Wissenschaftslandschaft verändert? Ich denke, der Wissenschaftler hat sich in einer Hinsicht sicherlich verändert. Für mich entfiel die den Studenten gegenüber bestehende Verpflichtung zur Studienreform. Die 68er und der Staat wussten ja alles besser. Es blieb die wissenschaftliche Neugier, der Trieb zur Entdeckung, zur Forschung. Allgemein ist sicher richtig, dass die Individualfreiheit nach 1968 größer geworden ist. Die Meinungsvielfalt und damit die Vielfalt der Forschungsthemen, allerdings weniger die wissenschaftliche Auseinandersetzung, haben mit der Vermehrung der juristischen Fakultäten zugenommen. Sicherlich werden die Themen Nationalsozialismus, Holocaust und Judenverfolgung vermehrt behandelt. Dies geschieht indessen positivistisch und in Einzelstudien. ${ }^{88}$ Die prinzipielle Auseinandersetzung ist jedenfalls verkümmert. Michael Stolleis' große „Geschichte des öffentlichen Rechts", deren drei erste Bände bis 1945 reichen, hat bislang keine Entsprechung für das Zivilrecht ${ }^{89}$ und das Strafrecht ${ }^{90}$ oder die anderen Disziplinen erfahren. Rechtswissenschaft und Recht sind noch unübersichtlicher geworden, als sie es früher waren. Es fehlt ihre kritische und historische Zusammenschau. Die politische Geschichte des deutschen Rechts ist bislang nicht geschrieben worden. Die 68er haben vielmehr die Aufgabe hinterlassen, sich mit dem Nationalsozialismus und der Nachkriegszeit auseinanderzusetzen.

Wie steht es mit dem wissenschaftlichen Ertrag der 68er-Bewegung in den einzelnen juristischen Disziplinen? Sind ihr die damaligen oder späteren Einzelleistungen

87 Erfolgte in Norddeutschland eine Abstimmung über die Ländergrenzen hinweg, etwa mit Hilfe der SPD oder der AsJ (Wassermann)?

88 Eine Ausnahme bildet Hubert Rottleuthner, der 1982 in Berlin die Vorträge „Recht, Rechtsphilosophie und Nationalsozialismus" organisiert und im Beiheft 18 des ARSP veröffentlicht hat. Ich habe in ihm das Familien- und Jugendrecht, mein Assistent Andreas Kranig das Arbeitsrecht behandelt, beide Male ohne die Rechtswissenschaft. Zur Gießener Reihe passten die Beiträge von Arthur Kaufmann und Rottleuthner (Rechtsphilosophie) und Buchner (Wirtschaftsrecht).

89 Stefan Grundmann/Karl Riesenhuber (Hg.), Der Sammelband „Deutschsprachige Zivilrechtslehrer in Berichten ihrer Schüler. Eine Ideengeschichte in Einzeldarstellungen" Bd. 1, Berlin u.a. 2008 bietet keinen Ersatz, sondern bleibt im Bereich der unkritischen Nekrologliteratur, vgl. meine Rezension, JoJZG 2 (2008), 72 ff.

90 Neu erschienen ist Thomas Vormbaum, Einführung in die moderne Strafrechtsgeschichte, Berlin u.a. 2009. 
hinzuzurechnen oder wären diese auch sonst erfolgt? Im Familienrecht ist die radikale Fragestellung, es in ein individualistisches Recht der Sexualbeziehungen und in ein Jugendrecht aufzulösen, ${ }^{91}$ nicht aufgegriffen worden. Das Arbeitsrecht ${ }^{92}$ ist bei der in der Weimarer Republik erreichten Teilung in Individual- und kollektives Arbeitsrecht stehen geblieben. ${ }^{93}$ Den Sammelband „Streitbare Juristen“ würde ich heute freundlicher als damals beurteilen. Die „,andere Tradition“, insbesondere der von den Nazis verfolgten Juristen, ist, auch mit der Gewichtung zugunsten der „Linken“, ein wichtiges Anliegen. Im Übrigen müssten die Zeitschriften „Demokratie und Recht“, die „Blätter für deutsche und internationale Politik“ und die „Kritische Justiz“94 auf ihren Ertrag kritisch durchgesehen und gewürdigt werden. Die Würdigung müsste indessen im Gesamtrahmen geschehen. Und dazu fehlt die andere Seite des Spektrums. Es bleiben nur Impressionen von ihr. Die „Deutschsprachigen Zivilrechtslehrer des 20. Jahrhunderts in Berichten ihrer Schüler" 955 haben mich sehr skeptisch gestimmt. Es scheint mir danach alles beim Alten geblieben oder sogar schlechter geworden zu sein.

Unverändert besteht das Anliegen, sich mit dem Nationalsozialismus auseinanderzusetzen. Es wurde nicht vom Anspruch bestimmt, die Wahrheit herauszufinden - und dies wäre bereits ein Wert an sich gewesen und hätte Folgen gezeitigt. ${ }^{96}$ Dazu erforderlich wäre gewesen, sich mit den Machtverhältnissen im „Dritten Reich“ auseinanderzusetzen. Hätten die 68er selbst damals den offenen selbstmörderischen Widerstand riskiert, und wie stand es um das Aushalten des ,freiwilligen Zwangs“, der häufig den Eintritt in die NSDAP erklärte. ${ }^{97}$ Endlich hätte man sich die stete Doppelrolle des Juristen bewusst machen sollen. Der Jurist ist in jedem Staat Handlanger des Regimes, aber auch Wächter über die Einhaltung der Grenzen der Herrschaftsmacht. ${ }^{98}$

91 Vgl. Thilo Ramm, Familienrecht Bd. I, München 1984 und Ders., Jugendrecht (wie Anm. $52)$.

92 Zu seiner Geschichte ab 1948 vgl. Thilo Ramm, Pluralismus ohne Kodifikation. Die Arbeitsrechtswissenschaft nach 1945, in: Dieter Simon (Hg.), Rechtswissenschaft in der Bonner Republik, Frankfurt 1994, 449, und personell und perspektivisch ergänzend, Wahsner (wie Anm. 56), 369.

93 Dabei würdige ich Wolfgang Däublers respektable Leistung durchaus, bleibe aber bei meiner früheren Beurteilung, dass sie innerhalb der Schranken der bestehenden Rechtsvorstellungen bleibt, vgl. weiter oben unter I. Wolfgang Däubler nimmt im Konzert der Meinungen den Platz des linken Gegenspielers ein und wird als solcher zitiert. Er ist in das System eingefügt.

94 Ich bekenne meine Antipathie. Sie ist eine zweifache: Ich bin damals 1968 auf die marxistische Tarnbezeichnung „kritisch“ hineingefallen und ich musste mich gegen ihre Zensur durchsetzen, als ich die Ringvorlesung „Nationalsozialismus und Recht“ zum Abdruck anbot.

95 Dazu Ramm (wie Anm. 91), 72.

$96 \mathrm{Ob}$ mit nachhaltiger Wirkung, ist allerdings zweifelhaft. Vgl. Bernd Rüthers, Geschönte Geschichten - Geschonte Biographien. Sozialisationskohorten in Wendeliteraturen, Tübingen 2001.

97 Allerdings gab es eine zeitweilige bei der Machtergreifung, die in etwa mit dem „Tag von Potsdam", des gemeinsamen Auftretens Hindenburgs und Hitlers gleichgesetzt werden kann.

98 Carl Schmitt, die Ikone des deutschen Staatsrechts, überschritt sie selbst und wurde Handlanger, wenn er 1934 bei den Röhm-Morden behauptete, „Der Führer schützt das Recht“, und mit dem Zitierverbot für jüdische Wissenschaftler die Wahrheit als Basis der Wissenschaft aufgab. 
Hat sich das Verhältnis des Deutschen zum Staat durch den glücklichen Triumph der Staatsmacht über die „Rote Armee Fraktion“ und die Integration der 68er verbessert? Sicher sind die Deutschen dafür dankbar gewesen, denn sie hatten von Mord und Totschlag genug. Aber haben sie sich mit „ihrem“ Staat seitdem identifiziert? ${ }^{99}$ Ich stelle diese Frage allgemein, auch für die Zeit des „Dritten Reichs“ und ebenso für die Weimarer Republik. Früher war ich in meinem Urteil über die Zeit vor 1933 sicherer gewesen und hatte kritisch angemerkt: Niemand hat seine Überzeugung für so wichtig gehalten, dass er dafür sein Leben geopfert hätte. Heute frage ich mich, ob er denn überhaupt eine Überzeugung hatte. Das Vernunftrepublikanertum reichte nicht aus, und ich würde das ,zu wenig“ ebenfalls Dolf Sternbergers ${ }^{100}$ und Richard von Weizsäckers angemahntem Verfassungspatriotismus entgegenhalten. ${ }^{101}$ Und wie hatte es eigentlich im Kaiserreich gestanden? Die Freiheit der Forschung und Lehre des Hochschullehrers, seine Unabhängigkeit gehörten zum Erbe des preußischen Freiheitskampfs gegen Napoleon I. und waren Teil des Rechtsstaats. Dieser war im Kaiserreich in der bestehenden Ordnung eingeschlossen, mit der sich der Jurist identifizieren konnte. Hat er dies getan oder nur als Geschenk der Staatsmacht entgegengenommen? Wie steht es endlich mit den heutigen Juristen und insbesondere den Rechtsprofessoren?

V. Noch eine allerletzte Frage: Was wäre eigentlich geschehen, wenn es die 68er nicht gegeben hätte? Schon 1966 hatte Helmut Lindemann das Grundgesetz als antiquiert bezeichnet und für eine zeitgemäße Verfassung plädiert. 1968 sprach Hans Dichgans vom „Unbehagen in der Bundesrepublik“ und stellte zwei Jahre später „Überlegungen zu einer Gesamtrevision“ des Grundgesetzes an. Waren dies nur vereinzelte Stimmen oder entstand eine Reformbewegung, die von den 68ern überrollt wurde und damit ein Ende fand? Auch die Antwort hierauf gehört zur Untersuchung.

Ich gelange zu keinem versöhnlichen Abschluss. Weder die 68er-Bewegung noch ihr Ende haben das fertig gebracht, was nach 1945 fällig gewesen ist: die bis zu den Wurzeln reichende tiefgreifende Auseinandersetzung der Deutschen mit ihrer Geschichte. Stattdessen ist sie inzwischen selbst historisiert worden. Die 68er sind Teil der deutschen Geschichte seit dem Zusammenbruch und dementsprechend gewürdigt worden, so bereits durch jene Zeitgenossen, die sie damals unterstützten. Sie war der Protest gegen die damalige Ordnung, blieb aber in ihr verhaftet und war unfähig, sie zu überwinden. Ihr Versagen im Einzelnen nachzuvollziehen, ist als Aufgabe der juristischen Zeitgeschichte gestellt. Aber bis diese Aufgabe erfüllt ist, wird es noch dauern.

99 Das Stichwort zu dieser Diskussion haben Dolf Sternberger und Richard von Weizsäcker mit ihrem „Verfassungspatriotismus“ gegeben. Es diente ursprünglich zur Zeit der deutschen Teilung als Ersatzbegriff, mit dem das Nationalgefühl auf die Verfassung des westdeutschen Teilstaats hingelenkt werden sollte.

100 Rede zur Fünfundzwanzigjahrfeier der Tutzinger Akademie von 29. Juni 1982, FAZ vom 31. August 1982.

101 Mein „Verfassungspositivismus“ war nur vernünftig. Die emotionale Beziehung zum Staat hatte schon der Nationalsozialismus zerstört und die Verfassung des westdeutschen Teilstaats konnte sie nicht wiederherstellen. 